\title{
Max Tech and Beyond: High-Intensity Discharge Lamps
}

\author{
Project Managers \\ Louis-Benoit Desroches \& Karina Garbesi \\ Environmental Energy Technologies Division
}

Author

Michael Scholand

N14 Energy Limited, Navigant Consulting Inc.

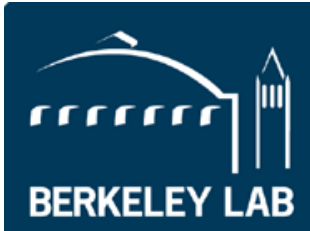

Lawrence Berkeley

National Laboratory

Lawrence Berkeley National Laboratory

One Cyclotron Road

Berkeley, CA 94720

April 1, 2012

The work described in this report was funded by the U.S. Department of Energy's Office of Energy Efficiency and Renewable Energy, Building Technologies Program under Contract No. DE-AC02-05CH11231. 


\section{Disclaimer}

This document was prepared as an account of work sponsored by the United States Government. While this document is believed to contain correct information, neither the United States Government nor any agency thereof, nor the Regents of the University of California, nor any of their employees, makes any warranty, express or implied, or assumes any legal responsibility for the accuracy, completeness, or usefulness of any information, apparatus, product, or process disclosed, or represents that its use would not infringe privately owned rights. Reference herein to any specific commercial product, process, or service by its trade name, trademark, manufacturer, or otherwise, does not necessarily constitute or imply its endorsement, recommendation, or favoring by the United States Government or any agency thereof, or the Regents of the University of California. The views and opinions of authors expressed herein do not necessarily state or reflect those of the United States Government or any agency thereof or the Regents of the University of California.

Lawrence Berkeley National Laboratory is an equal opportunity employer. 


\section{Acknowledgements}

The work described in this report was funded by the U.S. Department of Energy's Office of Energy Efficiency and Renewable Energy, Building Technologies Program under Contract No. DE-AC02-05CH11231.

The author would like to thank the author of the Lamp Tech website in the UK (http://www.lamptech.co.uk/index.html ) for granting permission to use their photos in this report, which appear as Figures 2-5, 2-6 and 2-7. 


\section{Table of Contents}

EXECUTIVE SUMMARY

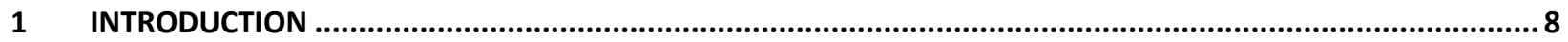

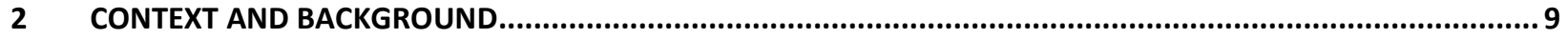

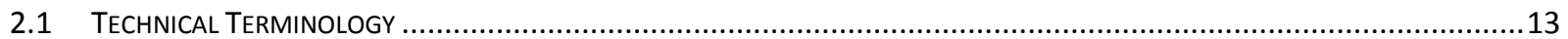

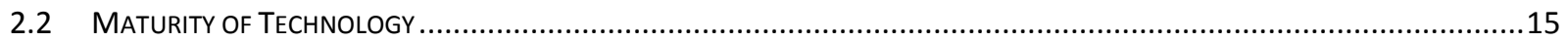

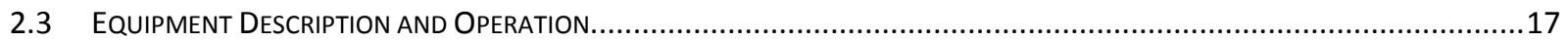

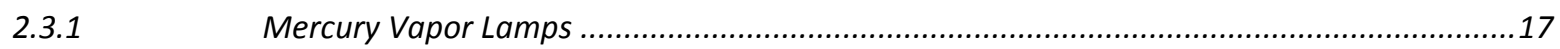

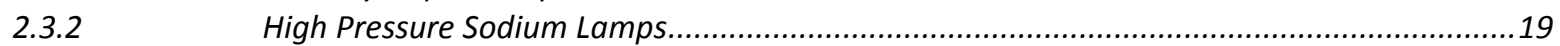

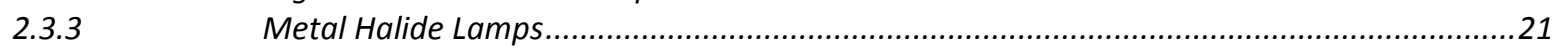

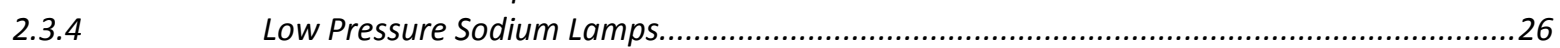

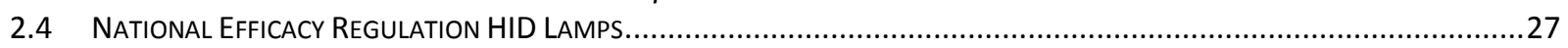

2.4.1 Energy Policy Act of 1992 - HID Lamp Determination.......................................................27

2.4.2 Energy Independence and Security Act of 2007 - Metal Halide Fixtures ............................28

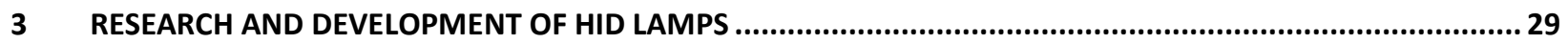

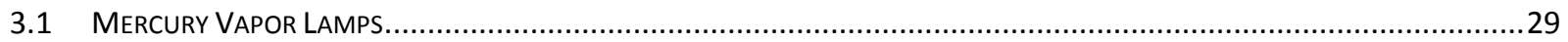

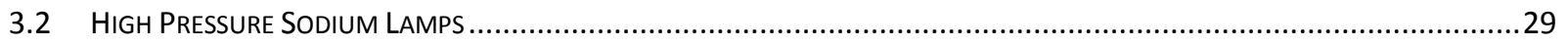

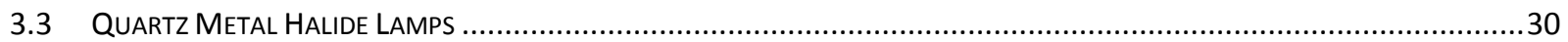

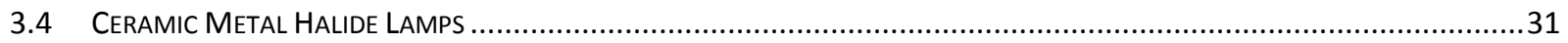

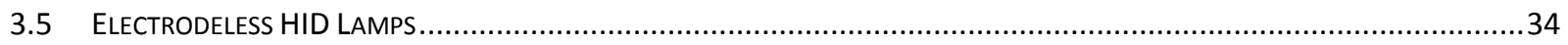

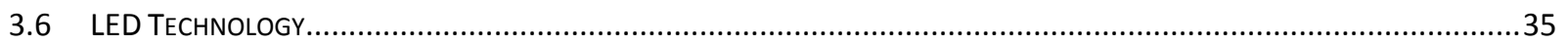

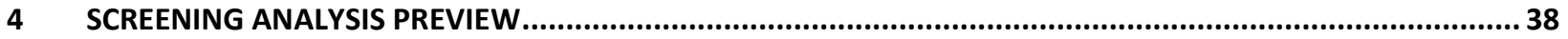

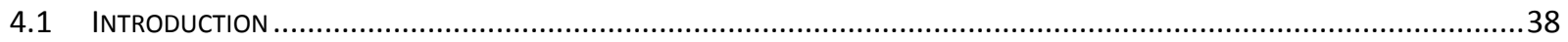

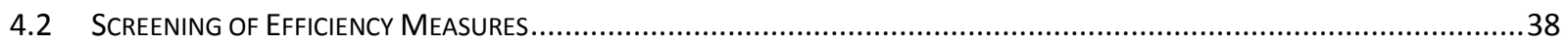

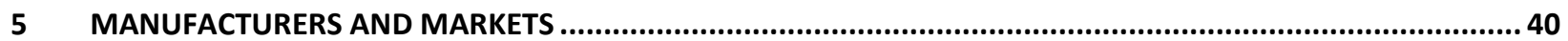

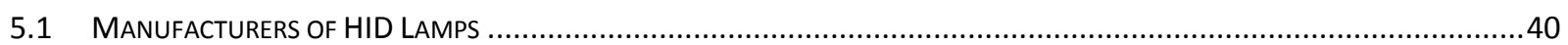

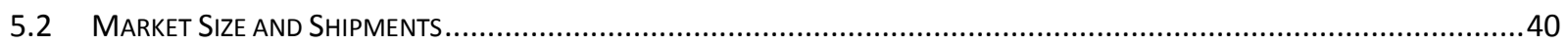

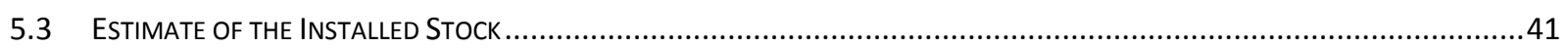

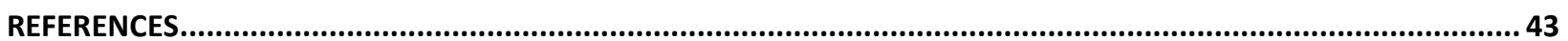

\section{List of Tables}

TABle 2-1. Sample of Typical Performance Attributes of Commercial HID LAMPS ..................................................11

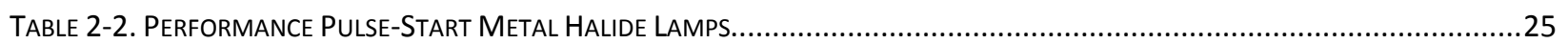

TAble 2-3. Performance Summary of Ceramic PulSe-Start Metal Halide Lamps ........................................................26

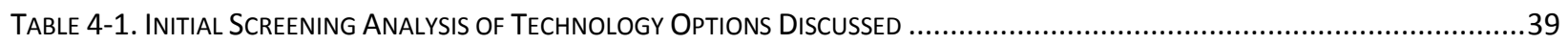

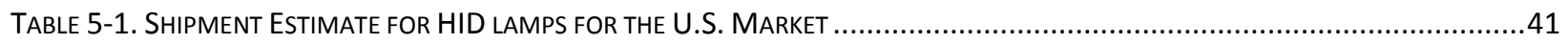

TABLE 5-2. ESTIMATE OF THE INSTALLED STOCK OF HID LAMPS IN THE US MARKET (000 UNITS).........................................42 


\section{List of Figures}

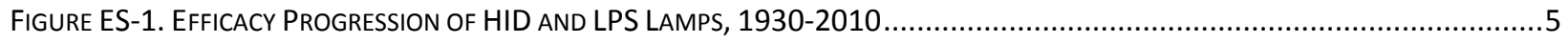

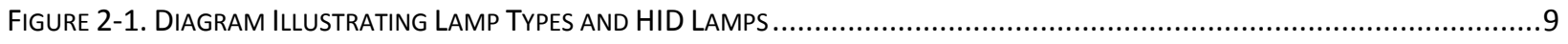

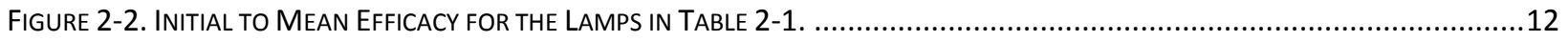

Figure 2-3. ShARES Of SECTORAL ENERGY USE BY LIGHTING TECHNOLOGY ................................................................13

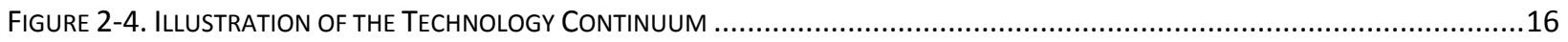

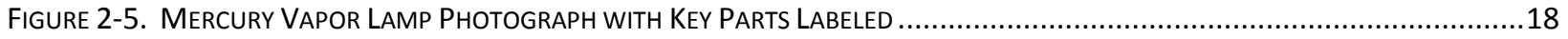

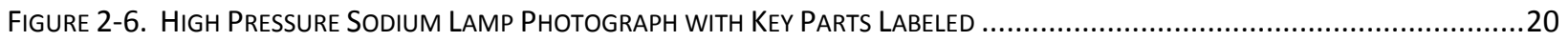

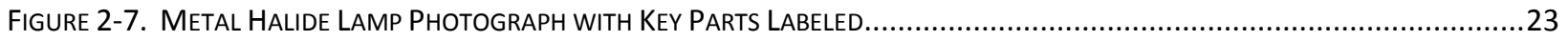

Figure 3-1. Projected OEM PRICE fOR WhITE LIGHT LED LAMP, INTEGRALLY BALLASTED ................................................36

\section{List of Acronyms}

$\begin{array}{ll}\text { ANSI } & \text { American National Standards Institute } \\ \text { CCT } & \text { Correlated Color Temperature } \\ \text { CFL } & \text { Compact Fluorescent Lamp } \\ \text { CRI } & \text { Color Rendering Index } \\ \text { DOE } & \text { Department of Energy } \\ \text { EU } & \text { European Union } \\ \text { GE } & \text { General Electric } \\ \text { HID } & \text { High Intensity Discharge } \\ \text { HPS } & \text { High Pressure Sodium } \\ \text { LED } & \text { Light Emitting Diode } \\ \text { LLD } & \text { Lamp Lumen Depreciation } \\ \text { LPS } & \text { Low Pressure Sodium } \\ \text { LPW } & \text { Lumens Per Watt } \\ \text { MH } & \text { Metal Halide } \\ \text { MV } & \text { Mercury Vapor } \\ \text { NEMA } & \text { National Electrical Manufacturers Association } \\ \text { US } & \text { United States } \\ \text { UV } & \text { Ultra Violet }\end{array}$




\section{Executive Summary}

High-intensity discharge (HID) lamps are most often found in industrial and commercial applications, and are the light source of choice in street and area lighting, and sports stadium illumination. HID lamps are produced in three types - mercury vapor (MV), high pressure sodium (HPS) and metal halide (MH). Of these, MV and MH are considered white-light sources (although the MV exhibits poor color rendering) and HPS produces a yellow-orange color light. A fourth lamp, low-pressure sodium (LPS), is not a HID lamp by definition, but it is used in similar applications and thus is often grouped with HID lamps. With the notable exception of MV which is comparatively inefficient and in decline in the US from both a sales and installed stock point of view; HPS, LPS and MH all have efficacies over 100 lumens per watt. The figure below presents the efficacy trends over time for commercially available HID lamps and LPS, starting with MV and LPS in 1930's followed by the development of HPS and MH in the 1960's.

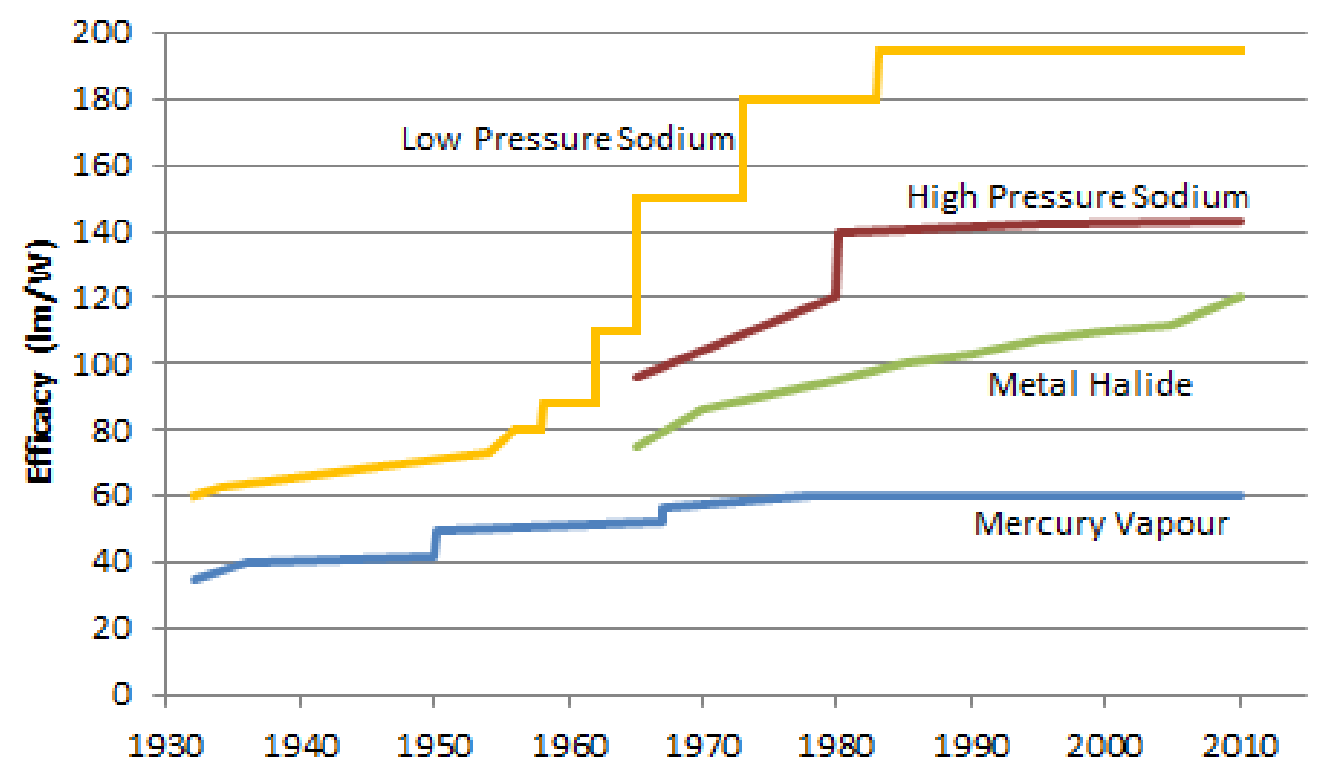

Figure ES-1. Efficacy Progression of HID and LPS Lamps, 1930-2010 Sources: Flesch, 2006; Hooker, 2010; GE Lamp Catalogue, 2010.

In HID lamps, light is generated by creating an electric arc between two electrodes in an arc tube. The particles in the arc are partially ionized, making them electrically conductive, and a light-emitting "plasma" is created. This arc occurs within the arc tube, which for most HID lamps is enclosed within an evacuated outer bulb that thermally isolates and protects the hot arc tube from the surroundings. Unlike a fluorescent lamp that produces visible light through downconverting UV light with phosphors, the arc itself is the light source in an HID lamp, emitting visible radiation that is characteristic of the elements present in the plasma. Thus, the mixture of elements included in the arc tube is one critical factor determining the quality of the light emitted 
from the lamp, including its correlated color temperature ${ }^{1}$ (CCT) and color rendering index ${ }^{2}$ (CRI).

Similar to fluorescent lamps, HID lamps require a ballast to start and maintain stable operating conditions, and this necessitates additional power beyond that used by the lamp itself. HID lamps offer important advantages compared to other lighting technologies, making them well suited for certain applications. HID lamps can be very efficient, have long operating lives, are relatively temperature-insensitive and produce a large quantity of light from a small package. For these reasons, HID lamps are often used when high levels of illumination are required over large areas and where operating and maintenance costs must be kept to a minimum. Furthermore, if the installation has a significant mounting height, high-power HID lamps can offer superior optical performance luminaires, reducing the number of lamps required to illuminate a given area. The indoor environments best suited to HID lamps are those with high ceilings, such as those commonly found in industrial spaces, warehouses, large retail spaces, sports halls and large public areas.

Research into efficacy improvements for HID lighting technologies has generally followed market demand for these lamps, which is in decline for MV and LPS, has reached a plateau for HPS and is growing for MH. Several manufacturers interviewed for this study indicated that although solid-state lighting was now receiving the bulk of their company's R\&D investment, there are still strong HID lamp research programs, which concentrate on MH technologies, with some limited amount of investment in HPS for specific niche applications (e.g., agricultural greenhouses). ${ }^{3}$ LPS and MV lamps are no longer being researched or improved in terms of efficacy or other performance attributes, although some consider MH HID lamps to be the nextgeneration MV lamp.

Thus, the efficacy values of commercially available MV, LPS and HPS lamps are not expected to increase in the next 5 to 10 years. MH lamps, and more specifically, ceramic MH lamps are continuing to improve in efficacy as well as light quality, manufacturability and lamp life. Within an HID lamp, the light-producing plasma must be heated to sufficiently high temperatures to achieve high efficiencies, without melting the electrodes or altering the operating conditions of the lamp. The research in ceramic MH has focused on the arc tube, the electrodes and the plasma, resulting in an innovation announced by Philips Lighting in 2009 called the “unsaturated lamp."

The unsaturated lamp addresses a problem experienced by standard ceramic MH lamps where a pool of liquid salt develops in the arc tube while the lamp is operating. This pool of liquid salt

\footnotetext{
${ }^{1}$ Correlated color temperature - the temperature of a blackbody radiator whose chromaticity most nearly resembles that of the light source. The metric for CCT is given in degrees Kelvin (K). Cooler temperatures (less than 3200K) are referred to as being "warm" in color as they contain more red light, while higher temperatures (in excess of $4000 \mathrm{~K})$ are referred to as being "cool" in color as they contain more blue light.

${ }^{2}$ Color rendering index - is a measurement of a light source's ability to render colors accurately. A perfect rendering of color compared with the incandescent reference source is given a maximum value of 100 . A limitation of this metric is that it is only applicable to light sources of the same correlated color temperature (CCT). In other words, CRI values of two light sources with different CCT cannot be compared.

${ }^{3}$ HPS lamp research focuses on agricultural applications because the lamp offers so many lumens per watt. The research is not about improving efficacy, but about optimizing other lamp performance issues for this application.
} 
limits the light characteristics of the lamp such as the efficacy and color quality, and reduces lamp lifetime. By making modifications to the arc tube, the pressure and the operating temperature, the unsaturated ceramic $\mathrm{MH}$ lamp resolves this issue by keeping all the halide salts in the gaseous phase, even while the lamp is dimming (down to 50\%). This innovation, coupled with an improved solution for sealing of the electrodes into the arc tube during manufacture, results in a much more robust seal for the electrodes in the arc tube.

By avoiding the liquid salt issue and improving the electrode seals, this new lamp design significantly reduces the reaction and attack on the ceramic arc tube, so lamp lifetime will improve. Plus, this technology has the potential to offer high performance characteristics such as fast run-up to full brightness ( $<30$ seconds), dimmability without color shift, longer operating life, mercury free lamps, hot re-strike and miniaturization. Following on from these innovations, researchers are now focusing on optimization and further improvement to the light quality and lamp efficacy.

Manufacturers are currently offering commercially available ceramic $\mathrm{MH}$ lamps that are operating at 120 lumens per watt (initial). Researchers interviewed agreed that they could envision this product being optimized and incrementally improved over the next 2 to 4 years to go from $120 \mathrm{~lm} / \mathrm{W}$ to $150 \mathrm{~lm} / \mathrm{W}$. Thus, by 2013-2014, it is expected that manufacturers would produce commercially available ceramic metal halide lamps that offer $150 \mathrm{~lm} / \mathrm{W}$, and which offer high quality white-light in a package that would be more than 20,000 hours of operating life. 


\section{Introduction}

Lawrence Berkeley National Laboratory (LBNL) recently conducted a study, entitled Max Tech and Beyond: Maximizing Appliance and Equipment Efficiency by Design, to assess the maximum and projected efficiency of a number of different energy using technologies and products (Desroches \& Garbesi 2011). The study takes 'max tech' (maximum technologically feasible) appliance efficiency engineering analysis as a starting point and creates an expanded catalogue of technology options for a wide range of appliances, equipment and systems. This report was prepared as part of that effort, focusing on high-intensity discharge (HID) lamps. This report takes into consideration the premium efficiency of products globally, the R\&D pathway, and information on prototype and design concepts under consideration that might further improve product efficiency.

Through this global study of HID lamp performance, this research will address both the maximum energy-efficiency levels achieved in the markets today and discuss technical innovations under development by industry and academia. The findings from this study cover both the maximum technologically feasible performance available today for HID lamps and the anticipated performance improvements that will be realized in the coming years. 


\section{Context and Background}

High intensity discharge (HID) lamps are a family of lamps that offer high lumen output from a relatively small source. These lamps are commonly used in applications as diverse as parking lot and street lighting through to warehouse and sports stadium lighting. There are three types of HID lamps - mercury vapor (MV), high pressure sodium (HPS) and metal halide (MH). In addition, there is another lamp-type called low pressure sodium (LPS) which technically is not a HID lamp, ${ }^{4}$ but from an application perspective is used in similar installations and therefore will be included in the scope of this study.

The diagram below illustrates the various classes of electric lamps, and those lamps that are circled in red are part of this study. These include the high-pressure mercury and high-pressure sodium gas-discharge lamps. The low-pressure sodium lamp is also circled in a dotted line because although it is not an HID lamp, it is discussed in this report.

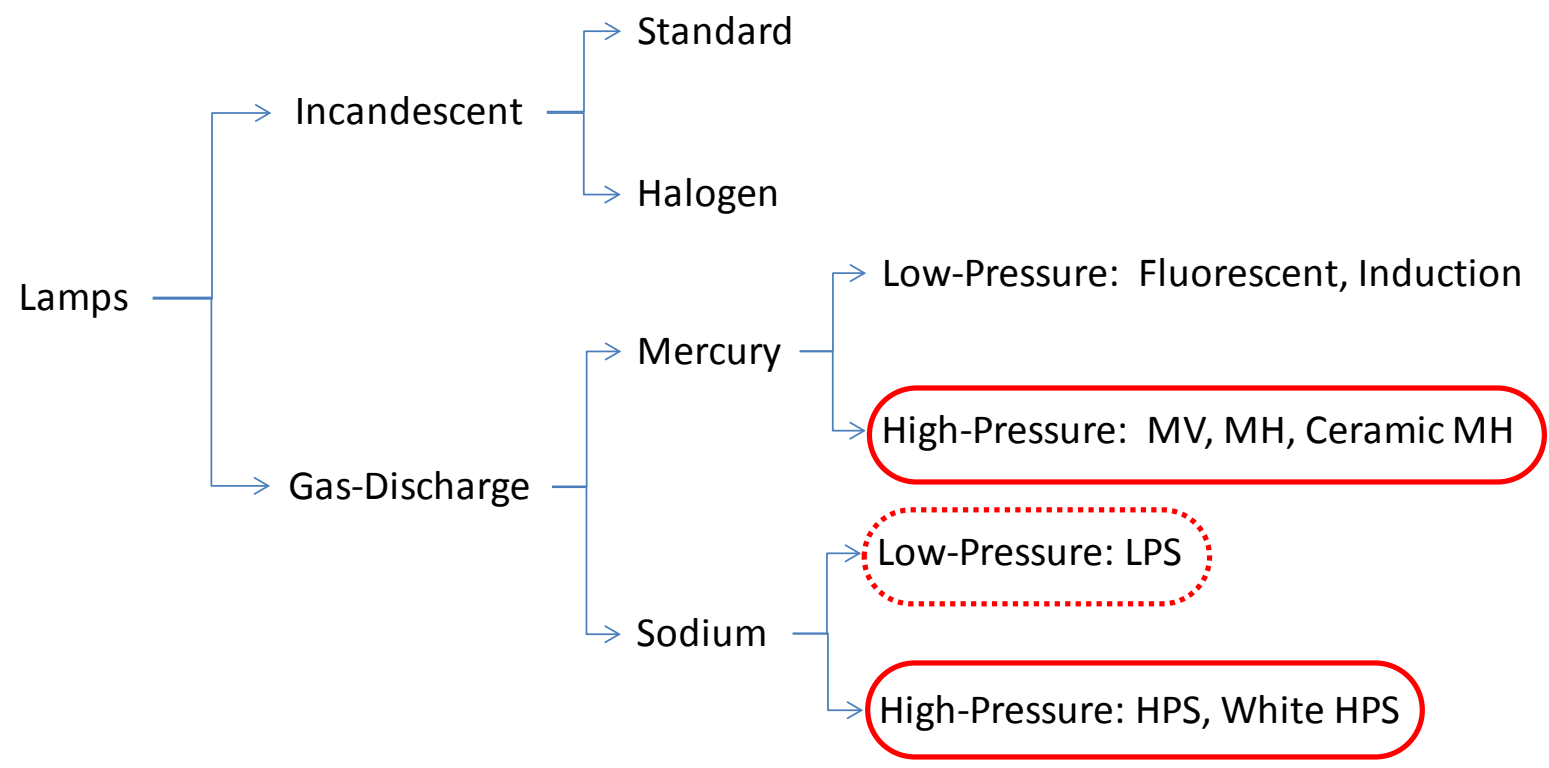

Figure 2-1. Diagram Illustrating Lamp Types and HID Lamps

In general terms, the mercury-based lamps which include mercury vapor, metal halide and ceramic metal halide produce a white-light. The sodium-based lamps produce a yellow-orange light, although there is a product called 'white HPS' that has other materials included in the highpressure arc tube which diversify the spectral emission producing a more 'white' light emission (but having a lower efficacy than standard HPS).

\footnotetext{
${ }^{4}$ HID lamps are defined as electric discharge lamps in which the arc tube wall temperature stabilizes a lightproducing arc, and the arc tube wall loading is in excess of 3.0 watts per square centimeter. LPS lamps have a lower level of arc tube wall loading, and therefore technically do not meet the definition of HID lamps. However, the lighting industry generally treats LPS lamps as HID lamps due to commonality in construction, operational characteristics, and application.
} 
HID lamps produce light from an intense electrical arc (called an electrical “discharge”) created between two electrodes. This process is similar to that of a fluorescent lamp, except that the visible light is emitted by the arc itself while the fluorescent lamp arc produces visible light through the phosphor coating on the tube wall. Some HID lamps incorporate a phosphor coating on the inside of the bulbs, but these coatings are generally only used either to provide improved color rendition or to increase the apparent size of the light source to reduce glare.

The following table depicts some of the commercially available HID lamps and typical performance levels for those lamps. The most efficient lamp in the table is the LPS lamp, which has an efficacy of 178 lumens per watt. While that value is numerically very high, the quality of the light is such that this lamp could not be used in many applications. LPS lamps have a color rendering index (CRI) of 5 and a correlated color temperature (CCT) of 1800 - both ratings are very low compared to quality white-light sources. The light emission from an LPS lamp is a deep orange light that is not aesthetically pleasing, and is not widely used anymore. The next most efficacious lamp is the HPS lamp, which has an initial efficacy of 127 lumens per watt for a 400 watt lamp and an slightly better CRI of 22. The metal halide lamp is the next most efficacious lamp, and it is the most efficient of the HID lamp 'white-light' sources. Metal halide lamps offer initial efficacies of 110 lumens per watt for a 400 watt pulse start, but with a 65 CRI - a significantly improved color rendering ability compared to HPS and LPS. The white HPS lamp offers a warmer white-light option, at 70 CRI and 2200K CCT, however its initial efficacy is 93 lumens per watt, nearly 20 lumens per watt lower than metal halide. The best HID lamps from a color rendering point of view are the ceramic metal halide $(\mathrm{CMH})$ lamps, which have a CRI of 90, exceeding all other HID lamps, including the standard metal halide and white HPS. 
Table 2-1. Sample of Typical Performance Attributes of Commercial HID Lamps

\begin{tabular}{|c|c|c|c|c|c|c|c|c|}
\hline Type & Base & $\begin{array}{c}\text { Power } \\
\text { (watts) }\end{array}$ & Coating & $\begin{array}{c}\text { Life } \\
(\mathbf{1 0 0 0} \\
\text { hrs })\end{array}$ & $\begin{array}{c}\text { CCT } \\
\left({ }^{\circ} \mathbf{K}\right)\end{array}$ & CRI & $\begin{array}{c}\text { Lumens } \\
\text { (initial/mean) }\end{array}$ & $\begin{array}{c}\text { Efficacy } \\
\text { (Im/ } / \boldsymbol{W}_{\text {nom }} \\
\text { initial/mean })\end{array}$ \\
\hline CMH & EX39 & 250 & Clear & 20 & 4100 & 90 & $23000 / 18400$ & $92 / 74$ \\
\hline CMH & EX39 & 350 & Clear & 20 & 4100 & 90 & $33000 / 26400$ & $94 / 75$ \\
\hline Pulse MH & E39 & 250 & Clear & 15 & 4200 & 65 & $23000 / 17000$ & $92 / 68$ \\
\hline Pulse MH & E39 & 400 & Clear & 20 & 4000 & 65 & $44000 / 35200$ & $110 / 88$ \\
\hline MH* & E26 & 175 & Clear & 10 & 4000 & 65 & $13600 / 8800$ & $78 / 50$ \\
\hline MH & E39 & 360 & Clear & 20 & 4300 & 65 & $36000 / 23500$ & $100 / 65$ \\
\hline HPS & E39 & 150 & Clear & $24+$ & 2000 & 22 & $16000 / 14400$ & $107 / 96$ \\
\hline HPS & E39 & 400 & Clear & $24+$ & 2100 & 22 & $51000 / 45000$ & $127 / 112$ \\
\hline White HPS & E39 & 400 & Clear & 15 & 2200 & 70 & $37400 / 34400$ & $93 / 86$ \\
\hline LPS & BY22d & 180 & Clear & 18 & 1800 & $\sim 5$ & 32000 & 178 \\
\hline MV & E39 & 175 & Clear & 20 & 5700 & 15 & $7850 / 6670$ & $45 / 38$ \\
\hline MV & E39 & 400 & Phos. & 20 & 3900 & 50 & $22600 / 15800$ & $56 / 40$ \\
\hline SB MV & E39 & 250 & Phos. & 12 & 3900 & 50 & $5000 / 3750$ & $20 / 15$ \\
\hline
\end{tabular}

*Lamp specifications are shown here for a vertical installation of this metal halide lamp.

Source: General Electric Lamp and Ballast Catalogue, Fluorescent Section updated May 2010; Philips Low Pressure Sodium Lamps Brochure, April 2003.

The MV lamps appear at the bottom of the table, where there are two standard MV lamps and one "self-ballasted" (SB) MV lamp. The efficacies of these three lamps are considerably lower than all the other HID lamps in the list, particularly the self-ballasted, which offers an efficacy value equivalent to an incandescent filament lamp.

Taking just the initial and mean efficacy values from the table above and plotting them for each of the lamp types, the following graph is prepared showing a comparison of lumen maintenance for each lamp type. The width of the red line represents a larger change in initial and mean efficacy, and thus a larger change in lumen maintenance. In this graph, the high efficacy value of LPS is immediately evident, as is its lumen maintenance - the initial and mean efficacy values are virtually the same. Standard MH lamps (called simply "Metal Halide" in this figure) have the worst lumen maintenance of the lamps shown below, with the greatest numerical difference between initial and mean lumens. Ceramic $\mathrm{MH}$ lamps exhibit the best lumen maintenance of the MH lamps, with the smallest differences between initial and mean lumens. The least efficient sources are the mercury vapor lamps, which operate at efficacies markedly lower than HPS and $\mathrm{MH}$. 


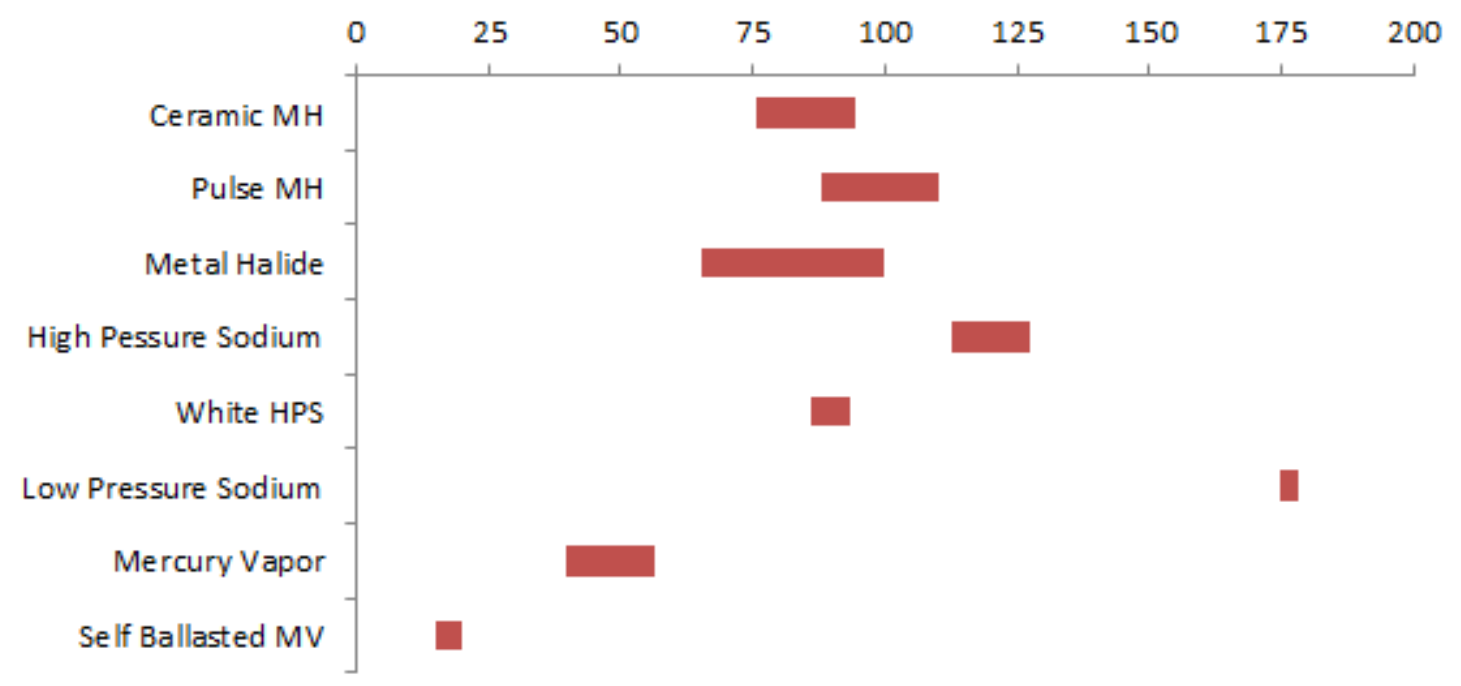

\section{Figure 2-2. Initial to Mean Efficacy for the Lamps in Table 2-1.}

From a research point of view, industry is continuing to invest in the improvement of $\mathrm{MH}$ technology, but investment in MV has stopped, and we did not identify any initiatives to improve the performance of HPS. In chapter 3 of this report, the methods developed and applied by manufacturers to improve the efficacy (i.e., lumens of visible light per watt of power consumed) of HID lamps are discussed.

From an application point of view, HID lamps offer important advantages compared to other conventional lamps. For instance, HID lamps can be very efficient, offer long operating lives, be reasonably temperature in-sensitive, and produce a large quantity of light from a small source. For these reasons, they have been used when high levels of light are required over large areas and where low operating and maintenance costs are important. In these installations, a sufficiently high ceiling is necessary to enable the light to be distributed by the luminaire across a large area, including spaces such as manufacturing facilities, retail superstores, warehouses, and sports halls. Their ability to produce a large amount of light in a small package and comparative temperature insensitivity make them the dominant light source for street and roadway lighting, as well as area and pathway lighting and other security and safety lighting applications. Furthermore, recent innovations that started with HID lamps used in automobile head-lamps are able to provide lighting in small retail establishments, such as directional ceramic metal halide HID lamps being used in place of halogen lamps.

The following figure presents the national energy consumption profile for HID lamps. These lamps consume less electricity than the installed stock of incandescent or fluorescent lamps, and they are commonly found in the outdoor stationary, commercial and industrial sectors. 


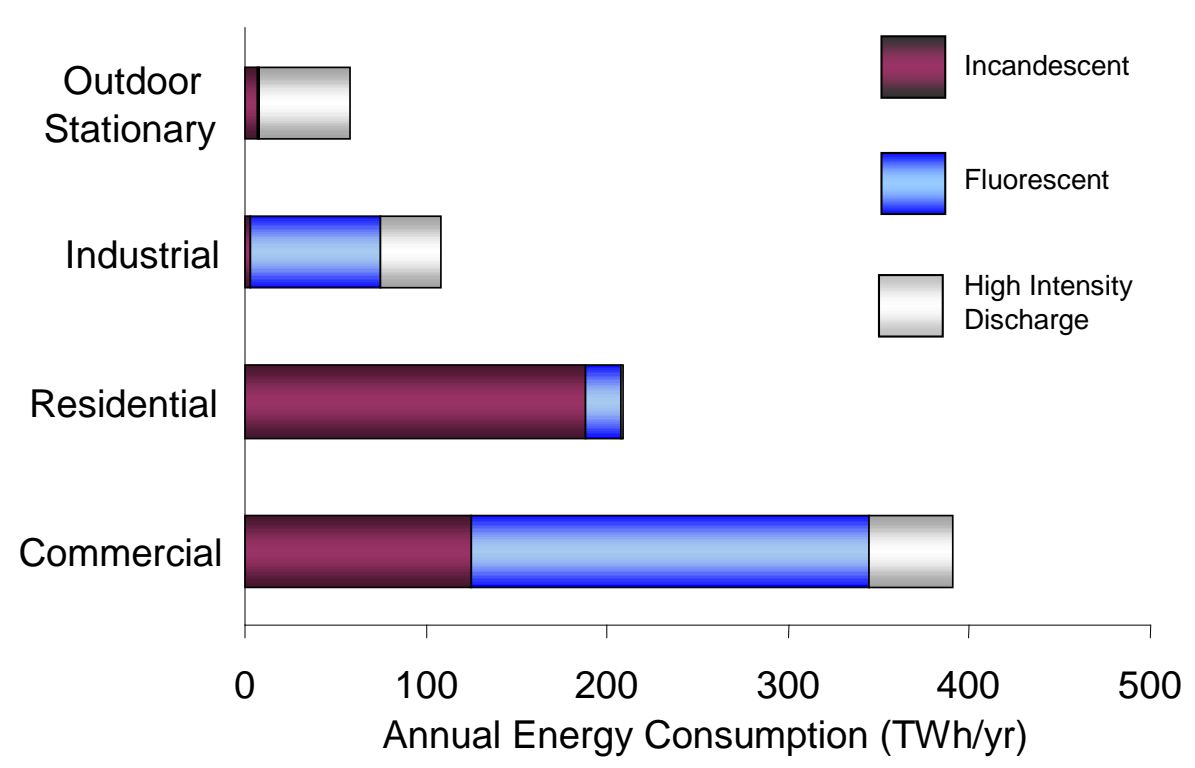

Figure 2-3. Shares of Sectoral Energy Use by Lighting Technology

Source: NCI, U.S. Lighting Market Characterization Volume I: National Lighting Inventory and Energy Consumption Estimate, 2002.

HID lamps constitute the primary light source for the outdoor stationary sector, where they supply illumination of roads, pathways, and large and small area lighting. In the industrial and commercial sectors, HID lamps can be found in high and low-bay fixtures illuminating large areas as well as in down-lights, building accent lights and parking lots.

\subsection{Technical Terminology}

This section identifies and defines some terms and concepts that are related to the HID lamp review and measures that will improve their efficacy.

- $\quad$ Ballast - a device used to obtain the necessary electrical conditions to start and operate an electric-discharge lamp, including an HID lamp.

- Color rendering index - is a measurement of a light source's ability to render colors accurately. A perfect rendering of color compared with the incandescent reference source is given a maximum value of 100 . A limitation of this metric is that it is only applicable to light sources of the same correlated color temperature (CCT). In other words, CRI values of two light sources with different CCT cannot be compared.

- Correlated color temperature - the temperature of a blackbody ${ }^{5}$ radiator whose chromaticity most nearly resembles that of the light source. The metric for CCT is given in degrees Kelvin (K). Cooler temperatures (less than 3200K) are referred to as being "warm" in color as they contain more red light, while higher temperatures (in

\footnotetext{
${ }^{5}$ Blackbody is defined as a temperature radiator of uniform temperature whose radiant excitance in all parts of the spectrum is the maximum obtainable from any temperature radiator at the same temperature. Such a radiator is called a blackbody because it absorbs all the radiant energy that falls upon it.
} 
excess of 4000K) are referred to as being “cool” in color as they contain more blue light.

- $\quad$ Efficacy - the measured visible light output of a lamp in lumens divided by the measured electrical power input in watts, expressed in lumens per watt (LPW). Efficacy provides a metric to compare the efficiency of white-light sources, although it does not account for ballast losses in the fluorescent system.

- $\quad$ Fixture - the housing into which a lamp and ballast are installed to create a finished luminaire. The fixture protects the lamp, and generally contains a socket(s) into which the lamp is inserted and usually manages or directs light distribution from the lamp.

- $\quad$ Foot-candle - a measure of illuminance equal to one lumen per foot square or 10.76 lux. One foot-candle is equivalent to the amount of light emitted by a single candle onto a plane orthogonal to the angle of incidence at a distance of one foot from the candle.

- $\quad$ HID lamp - an electric discharge lamp in which the arc tube wall temperature stabilizes a light-producing arc, and the arc tube wall loading is in excess of 3.0 watts per square centimeter. The following are examples of lamps that, when they meet these criteria, are considered HID lamps:

o A self-ballasted lamp, i.e., a lamp that contains the ballast within the lamp.

o A lamp in which radiation from mercury produces the major portion of the light. This type of lamp is commonly referred to as a mercury vapor lamp, and it typically operates at a partial vapor pressure in excess of $1.013 \times 10^{5}$ pascals (760 torr).

o A lamp in which radiation of metal halides and their products of dissociation, in combination with metallic vapors such as mercury, produces the major portion of the light. This type of lamp is commonly referred to as a metal halide (MH) lamp.

o A lamp in which radiation from sodium vapor produces the major portion of the light. This type of lamp is commonly referred to as a high-pressure sodium (HPS) lamp, and it typically operates at a partial pressure equal to or greater than $6.67 \mathrm{X}$ $10^{3}$ pascals (50 torr).

- Illuminance - is the density of luminous flux incident on an area. In other words, illuminance is the density of light determined by taking the total amount of light that falls on a plane divided by the total area of the plane.

- Lamp lumen depreciation - the intrinsic reduction in light output over the operating lifetime of a lamp, caused in part by non-recoverable factors such as the loss of emissive material on the electrodes, deposits of sputtered material on the inside of the glass bulb and the leakage of fill gas.

- $\quad$ Light - radiant energy that is capable of exciting the retina and producing a visual stimulation. Since the energy at each wavelength (i.e., visible light color) does not 
stimulate the human eye equally, to convert radiant energy to useful light for the human eye, each wavelength is weighted by the eye's sensitivity function, $V(\lambda)$.

- $\quad$ Lumen - the metric unit of luminous flux, defined photometrically as the luminous flux emitted within a unit solid angle (one steradian) by a point source having a uniform luminous intensity of one candela. A lumen measures the radiometric energy emitted from a light source weighted by the human eye’s sensitivity function, $V(\lambda)$.

- $\quad$ Luminaire - a complete lighting unit consisting of a lamp or lamps and ballast(s) (when applicable) together with a fixture (optics, housing and parts) designed to distribute the light, to position and protect the lamps, and to connect the lamps to the power supply.

- $\quad$ Rated life - under standard testing conditions, the time at which 50 percent of a large sample of HID lamps no longer operate (i.e., cease producing light).

- $\quad$ Spectral power distribution - a pictorial representation of the radiant power emitted by a light source at each wavelength or band of wavelengths in the visible region of the electromagnetic spectrum (380 to 780 nanometers). The SPD determines the CCT and CRI of the light source, and indicates the perceived color and quality of the light generated by the lamp.

- $\quad$ System efficacy - measurement of the overall energy performance of lamp-ballast combinations, calculated by multiplying the rated lamp lumens by the ballast factor and dividing the product by total input watts. The application of system efficacy is the same as for lamp efficacy, except that it takes into account the contribution of the ballast as it delivers power to the lamp from the main electricity supply.

\subsection{Maturity of Technology}

One critical facet of energy-efficiency measures being considered in this study is how close these new measures are to commercialization. The graphic below represents a technology continuum, used to classify a product and thus enable planning, including technical and business actions and decisions that are necessary to move a concept from a scientific phenomenon to a marketable product. In order for a technology to advance to the next stage along the continuum, it must meet criteria at each stage.

The technology continuum is divided into seven technology maturity stages described below. Figure 2-4 presents the seven technology maturity stages that comprise the technology maturity continuum. This graphic is developed for each of the technology options discussed in this chapter, with the gray diamond representing the stage for each technology option. In the example shown below, a given technology is classified as being at the Engineering Development stage. 
Figure 2-4. Illustration of the Technology Continuum

\begin{tabular}{|c|c|c|c|c|c|c|}
\hline \multicolumn{7}{|c|}{ Technology Maturity Stage } \\
\hline $\begin{array}{c}\text { Basic Science } \\
\text { Research }\end{array}$ & $\begin{array}{c}\text { Applied } \\
\text { Research }\end{array}$ & $\begin{array}{c}\text { Exploratory } \\
\text { Development }\end{array}$ & $\begin{array}{c}\text { Advanced } \\
\text { Development }\end{array}$ & $\begin{array}{c}\text { Engineering } \\
\text { Development }\end{array}$ & $\begin{array}{c}\text { Product } \\
\text { Demonstration }\end{array}$ & $\begin{array}{c}\text { Commercialization } \\
\text { and Sales }\end{array}$ \\
\hline & & & & & & \\
& & & & & & \\
\hline
\end{tabular}

The following text provides a brief description of each technology maturity stage:

- $\quad$ Basic Science Research - Fundamental science exploration is performed to expand the knowledge-base in a given field. Scientific principles (with data-empirical and/or theoretical derivation) are formulated and proven. The output from these projects would generally be peer-reviewed papers published in recognized scientific journals. Specific applications are not necessarily identified at this stage.

- $\quad$ Applied Research - Scientific principles are demonstrated, an application is identified, and the technology shows potential advantages in performance over commercially available technologies. Laboratory testing and/or math modeling is performed to identify the application(s), or provide the options (technical pathways) to an application. Testing and modeling add to the knowledge base that supports an application and point to performance improvements.

- $\quad$ Exploratory Development - A product concept addresses an energy efficiency priority. From laboratory performance testing, down select from alternative technology approaches for best potential performance, via selection of materials, components, processes, cycles, and so on. With laboratory performance testing data, down select from a number of market applications to the initial market entry ideas. This product concept must exhibit cost and/or performance advantages over commercially available technologies. Technical feasibility should be demonstrated through component bench-scale testing with at least a laboratory model of the concept.

- $\quad$ Advanced Development - Product concept testing is performed on a fully functional laboratory prototype - "proof of design concept" testing. Testing is performed on prototypes for a number of performance parameters to address issues of market, legal, health, safety, etc. Through iterative improvements of concept, specific applications and technology approaches are refocused and "down selected." Product specification (for manufacturing or marketing) is defined. Technology should identify clear advantages over commercially available technologies, and alternative technologies, from detailed assessment.

- $\quad$ Engineering Development - "Field ready prototype" system is developed to refine product design features and performance limits. Performance mapping is evaluated and testing of a field-ready prototype/system is carried out in a representative or actual application with a small sample in the field. The number of units is a function 
of unit cost, market influences, monitoring costs, owner/operator criteria, etc. Feedback from the user and technical data gathered from field trials are used to improve prototype design. Further design modifications and re-testing are performed as necessary.

- Product Demonstration - Operational evaluation of the demonstration units in the field is conducted to validate performance as installed. Third party monitoring of the performance data is required, although less data is recorded relative to the "field ready prototype" test in the previous stage. Pre-production units may be used. Size of demo is a function of unit cost, monitoring cost, etc., and involves relatively more visibility.

- $\quad$ Commercialization and Sales - The product is commercialized and is actively being marketed to customers.

\subsection{Equipment Description and Operation}

High Intensity Discharge or HID lamps are designed to produce light from an intense electrical arc (called an electrical “discharge”) created between two electrodes. This assembly is housed inside a transparent tube made out of quartz or ceramic and filled with various gas and metals that define the type of HID in question. The gas facilitates the formation of the electric discharge arc and the metals emit light once they are heated to the point of vaporization. The three main families of HID lamps are MV, HPS and MH. The light production mechanism in an HID lamp is similar to that of a fluorescent lamp, except that in an HID lamp, the visible light is emitted by the arc itself while the fluorescent lamp the visible light is emitted by the phosphor coating on the tube wall rather than the electrical arc. Similar to fluorescent lamps, HID lamps require control gear to start and maintain the arc, which necessitates additional power consumption beyond that used directly by the lamp itself.

\subsubsection{Mercury Vapor Lamps}

Mercury vapor lamps were the first HID lamps, appearing on the market in the 1930's. MV lamps are classified as a white-light HID source (albeit with a low CRI), producing a bluishgreen light. These lamps are often used in outdoor security, street, and landscape lighting. MV lamp shipments are in decline in the US, however they are expected to maintain some market share in certain niche applications where long life and low first cost are critical factors. MV lamps are available in wattages from 50 to 1000 watts, with CRI values ranging from 15 to 62 and CCTs of 2900 to $5700 \mathrm{~K}$. The higher CRI values are achieved using a phosphor coating which also reduces the efficacy of the lamp. The efficacy values typically range from 40 to 60 lumens per watt, and the operating lives range from 6000 to 28,000 hours.

The highest-efficacy and CRI MV lamps have a high vapor pressure and use separate (nonintegrated) ballasts, but in some parts of the world, self-ballasted lower-pressure "blended” 
mercury lamps ${ }^{6}$ are still common despite their very poor efficacy (14 to $29 \mathrm{~lm} / \mathrm{W}$ ) and poor light quality (50-60 CRI). These lamps are used primarily because of their low first-cost, no need for a ballast and longer lifespan than a standard incandescent lamp (i.e., 6000-12,000 hours).

The light output from MV lamps declines over the life of the lamp. The lumen output typically depreciates about 25 percent from its initial output at 50 percent of rated life. And it is not uncommon for MV lamps to continue operating long after their 'rated' life. The light output from the lamp continues to decline while the power consumption remains constant - meaning that efficacy decreases with use.

The figure depicts a photograph of a typical MV lamp. The outer bulb is made out of heat resistant glass with a small amount of nitrogen fill gas at a low pressure. The quartz arc tube is filled with argon and mercury, and there are two main electrodes that connect to the supporting structure. Finally, there is a lamp screw cap that is used to mechanically hold the lamp in place and electrically connect the lamp to the power circuit.

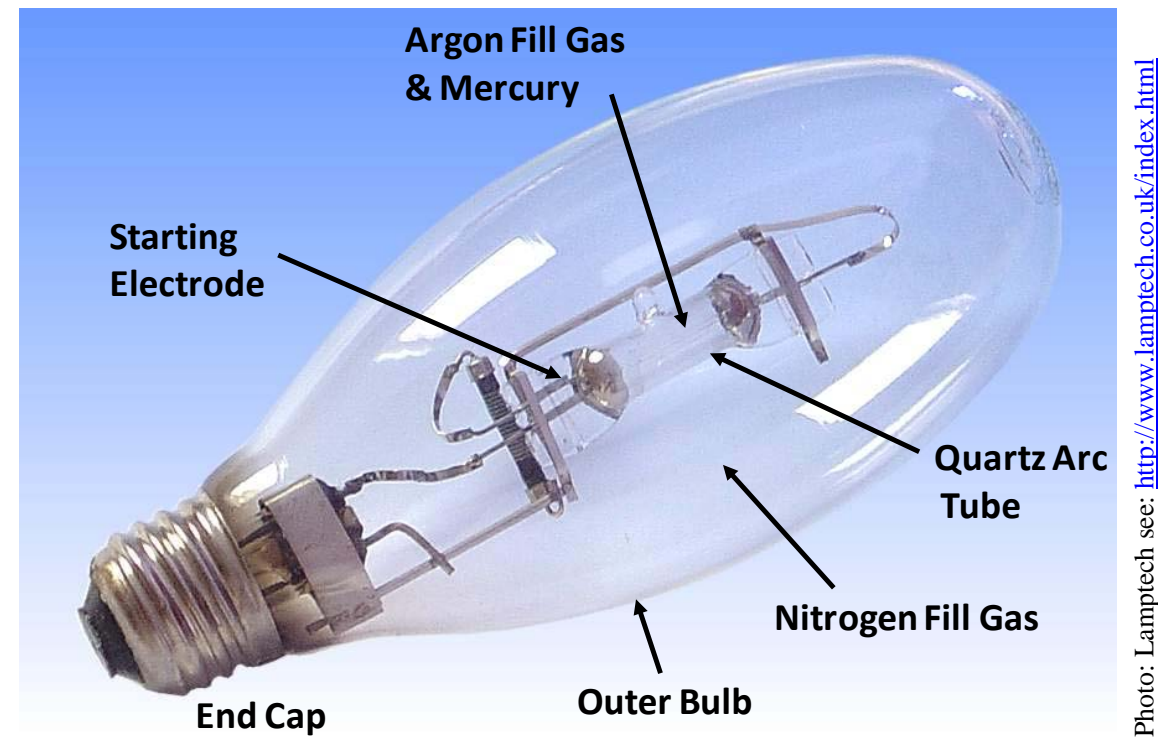

Figure 2-5. Mercury Vapor Lamp Photograph with Key Parts Labeled

MV lamps may operate with any of the commonly available MV and metal halide (MH) ballasts, without an igniter. MV lamps may use a reactor ( $\mathrm{RX}$ ) ballast, a high-reactance autotransformer (HX) ballast, a constant wattage autotransformer (CWA) ballast, or a constant wattage isolated transformer (CW) ballast. The ballast supplies sufficient starting current and voltage to allow the arc to strike and to stabilize after warm-up. In stable operation, the ballast limits the lamp current

\footnotetext{
${ }^{6}$ Blended light lamps do not require ballasts. They can convert $120 \mathrm{~V}$ incandescent lamp sockets to mercury vapor lamps by simply replacing the lamp. The longer life of the mercury lamp saves replacement labor costs and is a replacement for higher-wattage incandescent lamps. The range is from $160 \mathrm{~W}$ to $500 \mathrm{~W}$ and all bulbs have the phosphor coating. The lamps contain a tungsten filament which acts as the ballast for the mercury arc tube.
} 
to control the arc discharge and to prevent the lamp from self-destructing. The ballast is specific to each lamp type and power rating, and is designed to operate on a single voltage unless provided with input connections (taps) to select alternative input voltages.

When the circuit is energized, a small arc forms between the starting electrode and adjacent main electrode. The arc ionizes the fill gas and mercury vapor. When enough ions are present in the arc tube, the resistance drops and the main arc strikes between the two main electrodes. The current to the starting electrode stops as the resistance is higher than that between the main electrodes, and the main arc radiates light. To reach the necessary high vapor pressures within the arc tube, MV lamps require a warm-up time of approximately five to seven minutes. Restrike times are about as long, requiring five to seven minutes for the vapor pressure to come down to a level where the arc can restart.

MV lamps contain anywhere from 15 milligrams (mg) of mercury in 50-watt lamps up to $250 \mathrm{mg}$ in the 1000-watt units. Although other toxic materials are used in these lamps, these are present in trace amounts and are not considered hazards.

\subsubsection{High Pressure Sodium Lamps}

High pressure sodium lamps were introduced to the market in the 1960s, just before MH lamps. HPS lamps are the most efficacious HID light source, with initial efficacies from around 65 lumens per watt for 35-watt sources to 140 lumens per watt for 1000-watt sources. One hundred watt HPS lamps typically have initial efficacies above 100 LPW. LPS lamps have a higher efficacy, however technically they are not HID lamps because of their operational performance characteristics. By pressurizing ${ }^{7}$ the sodium vapor in the arc tube, the emission spectrum broadens, producing a golden light with low to mid-range CRI (i.e., approximately a CRI of 25). Due to the unappealing deep orange color of LPS and the slightly better CRI of HPS, there has been a shift toward HPS lamps particularly in installations where color differentiation is not critical - such as outdoor street lighting and area lighting, and some indoor industrial applications. HPS lamps also provide visibility and a sense of security when illuminating pedestrian areas such as public access areas, subways, and parks. There is no significant UV emission, and thus these lamps can be safely used in open luminaires without the need for supplemental UV emission adsorption.

HPS lamps are available in wattages from 35 up to 1000 watts; however the most commonly used wattages range from 50 to 400 watts. Similar to MV lamps, HPS lamps have an inner arc tube and an outer bulb construction. The outer bulb contains a vacuum. The electrical arc tube is ceramic, ${ }^{8}$ containing electrodes, sodium and mercury amalgam, and a small amount of xenon gas. An amalgam reservoir inside the arc tube helps to stabilize the pressure in the arc tube. This design feature allows HPS lamps to operate in any physical orientation (i.e., vertical or

\footnotetext{
${ }^{7}$ High pressure sodium lamps are so called to distinguish them from LPS lamps, but the actual arc tube pressure is not much above atmospheric pressure. This means there is no violent failure should an arc tube rupture.

${ }^{8}$ The ceramic arc-tube is designed to withstand temperatures up to $1300^{\circ} \mathrm{C}$, to transmit more than $90 \%$ of the visible spectrum, and to be free of any pores that might leak or weaken the tube. The reason for using ceramic is due to its natural ability not to deteriorate in the presence of hot sodium.
} 
horizontal), simplifying stocking and installation. The electrodes are double layer tungsten coils with rare earth oxides similar to other HID lamps. HPS lamps do not have a starting electrode, instead the external control gear includes an ignitor that provides a high voltage pulse to initiate the arc.

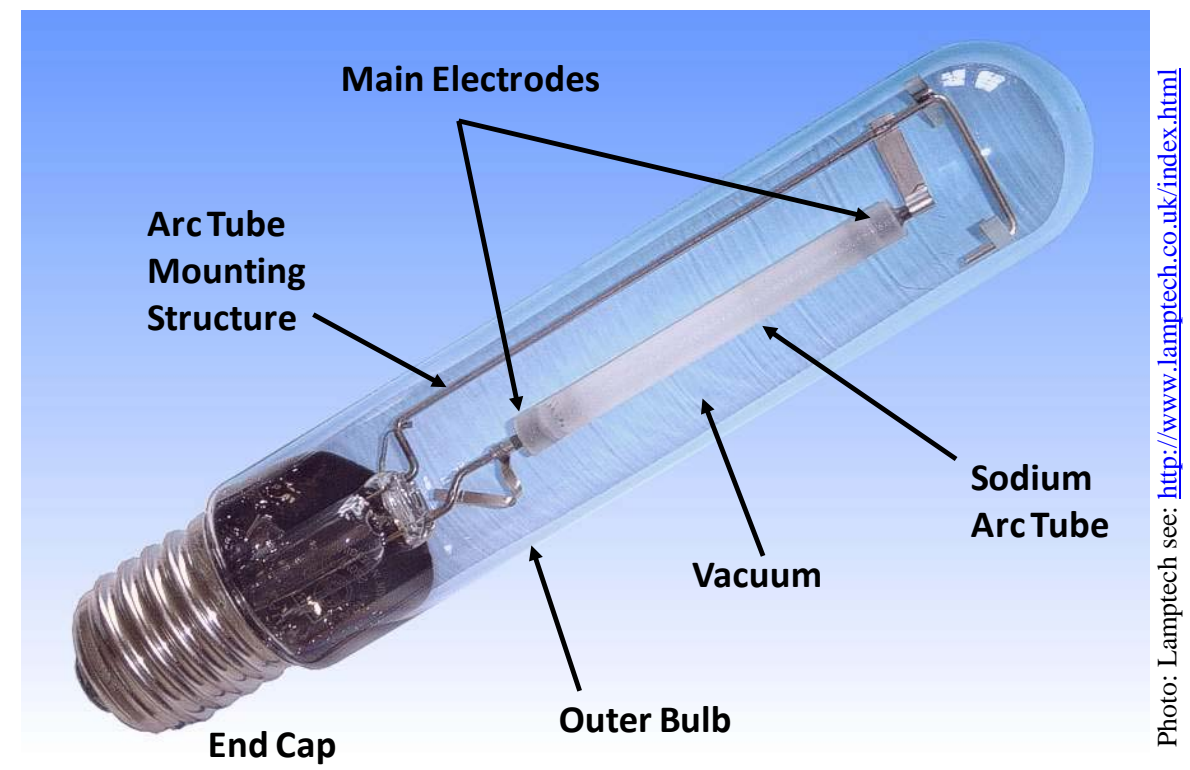

Figure 2-6. High Pressure Sodium Lamp Photograph with Key Parts Labeled

The starting high voltage pulse for a 400W lamp is approximately 2500-4500 volts and lasts for one microsecond. This short duration means little energy is used, but it is adequate to ionize the xenon gas and start the arc. Once the current is flowing through the ionized gas, the heat from the arc evaporates the amalgam mixture in the arc tube. The warm-up period of HPS lamps is approximately five minutes, which is longer than MH lamps; however the hot re-strike period is shorter than $\mathrm{MH}$ lamps, typically less than one minute.

Unlike other HID lamps, whose lamp voltage remains relatively constant throughout its lifetime, the HPS arc tube voltage increases over its operational life. This is due to the loss of sodium over the operating lifetime of the lamp, which causes the voltage to increase as the ratio of sodium to mercury in the arc tube changes. Thus, HPS ballasts must compensate for the change in operating voltage to maintain the desired light output over the lamp lifetime. At the end of the lamp's life, the operating voltage will rise to a level beyond the ballast's ability to sustain the arc. At this point, the lamp will start, warm up to full brightness, and extinguish. The repeating of this restart and extinguish sequence is known as cycling, and represents the end-of life of a HPS lamp. If the cycling is allowed to continue for too long (i.e., the HPS lamp is not replaced within a reasonable amount of time), the continuous high voltage pulses generated by the ballast for each restart of the lamp could cause premature failure of the ballast. Manufacturers have produced non-cycling HPS lamps and HPS ballasts to address this issue. 
HPS lamps have CRIs ranging from 21 for standard lamps up to 83 for white-light HPS lamps. The CCT values range from 1900 to $2500 \mathrm{~K}$, all very warm CCT values - hence the golden white light. The lamps have typical operating lifetimes of between 5,000 and 28,500 hours, although some long life HPS lamps offer 40,000 hours of life. These long-life lamps have two arc chambers operating in parallel (both physically and electrically). The lamps will alternate firing and thus extend the operating life of the lamp by having each arc tube only used only half the time.

Color-corrected HPS lamps produce a whiter light are also available with CRIs as high as 83, but as with other HID lamps, improving the CRI reduces efficacy. Despite this, white-light HPS offers an efficacy that is much higher than that of MV lamps. This type of HPS lamp is suitable for certain indoor applications, particularly retail display where the products on display are better illuminated with light containing a high proportion of red.

Manufacturers also offer an HPS lamp which can be installed directly into a fixture that contains a mercury vapor ballast. This product offers end-users a simple way of upgrading MV lamps to a more efficient HID lamp without having to change the control gear. The HPS lamps are able to do this because they incorporate an internal ignitor. Two retrofittable lamps that are offered that are a $110 \mathrm{~W}$ can replace $125 \mathrm{~W}$ MV lamps, producing $40 \%$ more light at $15 \mathrm{~W}$ less power consumption, and a 215W HPS lamp replacing a 250W MV lamp which also produces about $40 \%$ more light while consuming 35 fewer watts.

\subsubsection{Metal Halide Lamps}

MH lamps are widely considered to be the HID lamp type that will eventually replace all HID lighting applications. MH lamps offer a compelling combination of quality, performance, efficiency and flexibility for white-light applications. In addition, they are capable of producing light in a variety of color temperatures with good color rendering. $\mathrm{MH}$ lamps are available in a broad range a wattages, from as low as 20 watts to more than 1000 watts.

A MH lamp operates in a similar way to a MV lamp; the major difference being that the metal halide arc tube contains various metal halides in addition to mercury and argon. When the lamp attains full operating temperature, metal halides in the arc tube partially vaporize. As halide vapors approach the high-temperature central core of the discharge, they dissociate into halogen and metals, with the metals radiating their light spectrum. As halogen and metal atoms move near the cooler arc tube wall by diffusion and convection, they recombine and the cycle repeats. The halides are selected to fill in the gaps in the mercury spectrum to provide a light source having much better quality white-light emission.

The use of metal halides inside the arc tube presents two advantages. First, metal halides are more volatile at arc tube operating temperatures than pure metals. ${ }^{9}$ This allows for the introduction of metals with desirable emission properties into the arc at reasonable arc tube temperatures. Second, those metals that react chemically with the arc tube are in the form of a halide, which is much less reactive with quartz or ceramic, minimizing corrosion of the arc tube.

\footnotetext{
${ }^{9}$ The metals must be added as halides because the metals themselves usually have too low a vapor pressure to enable them to be part of the discharge, while halides are vaporized much more easily.
} 
Industry continues to invest in $\mathrm{MH}$ lamp technology research, and improvements are being made in almost every aspect of its performance. The operating life of a pulse-start metal halide (PMH) lamp is now approaching the operating life of HPS and MV lamps, particularly if the PMH lamp operates with an electronic ballast. And, with MH lamp efficacy levels approaching those of HPS lamps, MH lamps are competing with HPS lamps in outdoor applications such as roadway, parking, security, and pedestrian walkway lighting. Furthermore, the spectral light emission is far superior to HPS, with CRI values typically 85 or better through advancements in arc tube chemistry, design and materials.

The variety of spectral distribution patterns available from $\mathrm{MH}$ lamps offers an advantage over HPS lamps in outdoor lighting applications. As the level of light decreases, the spectral response of the human eye shifts to the scotopic visibility function. The result is that peripheral visibility under MH sources may be greater than HPS sources which provide equivalent visibility under higher light level (photopic) conditions. Outdoor lighting installations can take advantage of this phenomenon where specified light levels are low.

The small physical dimensions and high intensity of the MH lamp arc make it more of a point source than HPS, enabling better application-specific light distributions through precise optical reflector designs. High-wattage (above 1000 watts) MH lamps appear in stadiums, in searchlights, and in any other application that requires powerful white light. MH lamps in lowwattage (below 175 watts) configurations illuminate a variety of applications such as billboard displays, recessed lighting, and retail display / track lighting.

MH lamp construction is similar to that of MV lamps, although they are usually smaller for equal wattages. The arc tube is typically made of either fused quartz or ceramic, and contains a starting gas (usually argon), mercury, and a mixture of metal halide salts to create the desired spectral emissions. $\mathrm{MH}$ arc tubes operate at a higher temperature and pressure than their $\mathrm{MV}$ counterparts. The use of ceramic materials in arc tube construction enables higher operating temperatures and pressures, resulting in improved efficacy, CRI, and color stability.

The arc tube is housed within an elliptical-shaped outer bulb, usually made of borosilicate glass. The outer bulb protects and buffers the arc tube and internal electrical connections from the environment. The outer envelope contains low-pressure inert gas (i.e., nitrogen) or a vacuum, which not only helps minimize oxidation of internal components, but also provides a margin of safety against the threat of implosion. The outer envelope also provides additional thermal buffering for a more stable arc temperature. Finally, the glass itself absorbs the majority of UV emissions from the $\mathrm{MH}$ arc tube.

Like other HID lamps, MH lamps typically have screw bases (medium or mogul) made from brass, nickel, or special alloys to minimize corrosion. A characteristic of $\mathrm{MH}$ arc tubes is that they can take different forms and can be made from different materials. The most commonly available configuration is the probe-start MH lamp. In typical probe-start MH lamps, the arc tube is shaped into what is called the classic pinched-body arc tube. The lamp body must also contain a system that provides for either shorting the starter electrode to the main electrode or opening the starter electrode circuit after ignition. This prevents electrolysis in the fused silica 
between starting and operating electrodes. Lamps of this configuration are referred to as probestart $\mathrm{MH}$ lamps, in reference to the presence of the starter probe in the arc tube, and these are typically the least efficient MH lamps.

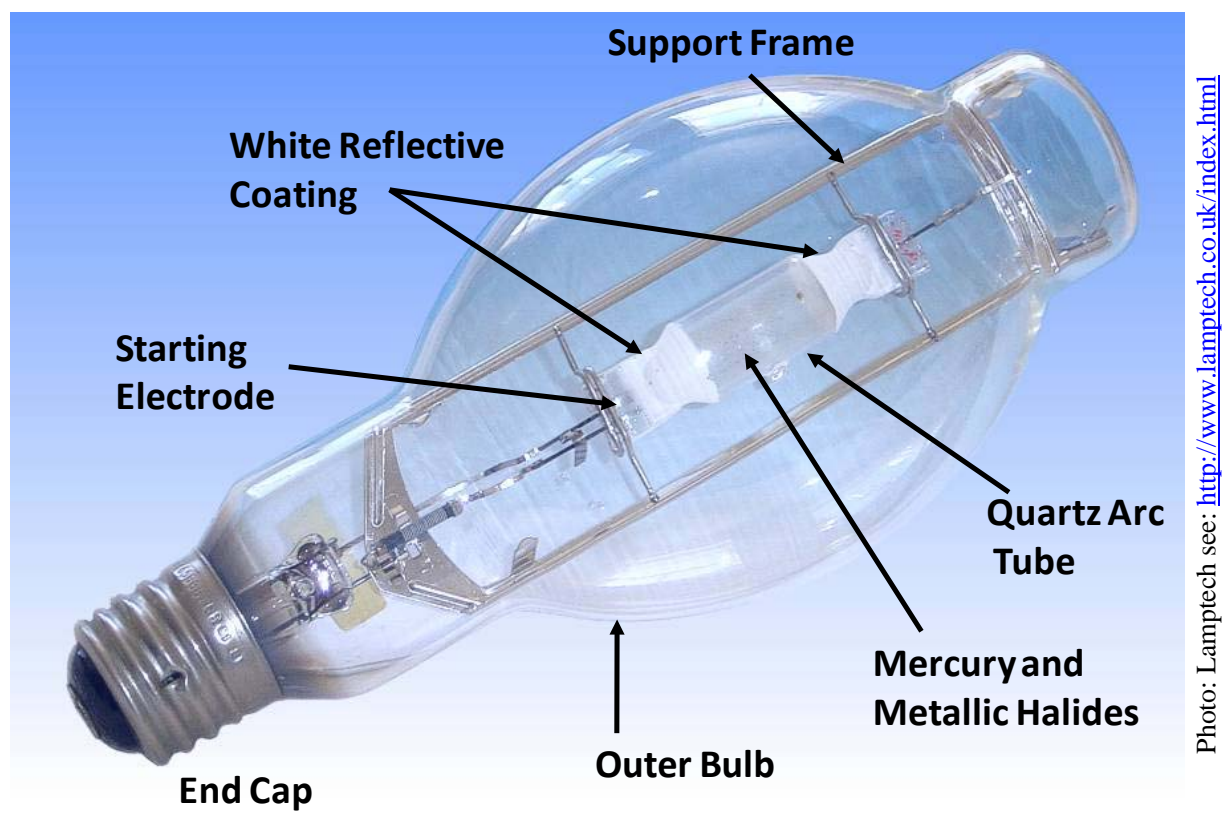

Figure 2-7. Metal Halide Lamp Photograph with Key Parts Labeled

Manufacturers designate an orientation for $\mathrm{MH}$ lamps: vertical, horizontal or universal (able to operate in any position). This is important because in horizontal $\mathrm{MH}$ lamps for example, the arc discharge bows away from the axis of the arc tube due to convection currents. The metal halide pool (which is liquid) moves to the center of the arc tube. The bowed arc moves farther from the metal halides than when the lamp is vertical, causing them to cool. This lowers vapor pressure of the halides and decreases the concentration of metals in the arc, resulting in a loss of light. And, as the bowed arc moves closer to the top of the arc tube wall, this causes the tube wall temperature to increase. The higher wall loading on the arc tube material can result in a decrease in life of approximately 25 percent. Therefore, manufacturers change the shape of the arc tube (e.g., bowed shape) or placement of the electrodes (e.g., off-set) to compensate for operating position.

Because physical operating orientation of the lamp affects performance, $\mathrm{MH}$ lamps are typically life-rated and lumen-rated in the appropriate operating position. MH lamps classified as universal orientation (able to operate in any orientation) achieve their rated performance in the vertical position. Commercially available MH lamps have efficacies of 75 to $125 \mathrm{LPW}$, or approximately twice as efficient as MV lamps. Almost all varieties of white-light MH lamps have color-rendering properties (approximate CRI of 70) superior to phosphor-coated MV lamps and HPS lamps. This unique capability results from the manufacturer's ability to tailor the spectral outputs of the MH lamps by changing the types and doses of the halides. 
Metal halides in these lamps have characteristic emissions that are spectrally selective. Some metals produce visible radiation in narrow spectral bands, generating specific colors - lithium (Li) for red, sodium ( $\mathrm{Na}$ ) for yellow-orange, thallium (Tl) for green, and indium (In) for blue. Other metals, such as tin (Sn), holmium (Ho), thulium (Tm) and dysprosium (Dy) when introduced as halides, radiate predominantly as molecules, providing continuous band spectra across the visible spectrum. Two common combinations of halide mixes in MH lamps are 1) scandium and sodium iodides, and 2) dysprosium, holmium, and thulium rare-earth iodides. Various combinations of these halides can create a wide range of CCT and CRI for these lamps. For example, the scandium-sodium system can produce CCT values from 2500K to 5000K by varying blend ratio and arc tube operating temperature.

Probe-start MH lamps, which are not as efficient as PMH lamps, typically employ pinch-seal designs that have a starter electrode (or probe) to help initiate the arc. When operated to specifications, probe-start lamps have a rated life from 10,000 to 20,000 hours with an efficacy of approximately 90 LPW. LLD is about 35 percent at 40 percent rated life.

PMH lamps have higher starting gas fill pressure to decrease starting time and minimize transport of electrode material to the wall. This keeps the arc tube cleaner, and improves lumen maintenance and life as compared to probe-start lamps. Some manufacturers shape the arc tube for additional benefits. These improvements result in longer life (up to 50 percent longer) and improved LLD (up to 33 percent better) compared to traditional probe-start MH lamps.

PMH lamps lack the secondary electrode found in probe-start MH lamps, resulting in different electrical requirements and performance. Consequently, a high-voltage pulse (typically in excess of 3 kilovolts) applied directly across the main electrodes initiates the arc. Igniters generate these starting pulses, and these lamps start faster than their probe-start counterparts. The higher voltages generated by the igniter allow the lamps to re-strike at much higher vapor pressures. This reduces the required cooling time for re-ignition to take place. The warm-up and re-strike time are in the range of one to four minutes and two to eight minutes respectively. That is an improvement over the typical probe-start $\mathrm{MH}$ warm-up time of 2 to 15 minutes and re-strike time of 5 to 20 minutes. The warm-up and re-strike times of PMH lamps are also better than those of typical MV and HPS lamps. 
Table 2-2. Performance Pulse-Start Metal Halide Lamps

\begin{tabular}{|c|c|c|c|c|}
\hline Lamp Power & $\mathbf{C R I}$ & $\mathbf{C C T}$ & $\begin{array}{c}\text { Initial Efficacy } \\
\text { (lumens per watt) }\end{array}$ & $\begin{array}{c}\text { Mean Efficacy } \\
\text { (lumens per Watt) }\end{array}$ \\
\hline (watts) & $\mathbf{( R a )}$ & $\mathbf{( { } ^ { \circ } \text { Kelvin) }}$ & $60-69$ & $36-42$ \\
\hline 70 & $60-70$ & $2900-3700$ & $64-79$ & $40-57$ \\
\hline 100 & $70-82$ & $2900-4200$ & $76-90$ & $49-62$ \\
\hline 150 & $70-82$ & $2900-4200$ & $77-93$ & $50-73$ \\
\hline 175 & $60-88$ & $2900-4300$ & $91-100$ & $69-74$ \\
\hline 200 & $65-75$ & $3200-4000$ & $90-95$ & $64-68$ \\
\hline 250 & $65-70$ & $3800-4200$ & $80-92$ & $55-68$ \\
\hline 320 & $60-70$ & $3600-4400$ & $87-106$ & $52-78$ \\
\hline 350 & $65-70$ & $3600-4300$ & $91-104$ & $66-77$ \\
\hline 360 & $65-70$ & $3400-4000$ & $94-97$ & $63-65$ \\
\hline 400 & $65-70$ & $3600-4000$ & $90-110$ & $39-88$ \\
\hline 750 & $65-70$ & $3600-4100$ & $96-109$ & $72-89$ \\
\hline 1000 & $65-70$ & $3700-4000$ & $105-110$ & $82-96$ \\
\hline
\end{tabular}

Source: GE and Osram-Sylvania Catalogues, 2010.

Arc tube research led to the development of the ceramic arc tube. The use of ceramic arc tubes further enhanced some of the metal halide lamp's properties. Due to the fact that ceramic can withstand higher temperatures than quartz glass, manufacturers are able to make arc tubes that have higher wall temperatures thereby evaporating more of the metal halide salts into the gas arc and allowing for more efficient operation and better quality light. Furthermore, ceramic arc tubes can be produced with smaller dimensional tolerances, reducing the variation in the optical and electrical parameters. As a material, ceramic is less susceptible to attacks from the corrosive metal halide filling, enabling a longer service life compared to $\mathrm{MH}$ lamps that use quartz arc tubes. Finally, manufacturers have also innovated on the shape of the ceramic tube, to further improve the overall performance of these lamps.

This technology is currently available only in wattages up to 400 watts. Improvements in ceramic arc tube design will soon make higher-power versions available. When operated to specifications, the PMH lamps with ceramic arc tubes have a rated life from 9,000 to 15,000 hours, with an efficacy ranging from 80 to 100 lumens per watt. Most notably, in contrast to pulse metal halide, the ceramic metal halide have excellent CRI ranging from 80 to 95, enabling it to be used widely in retail display and other commercial lighting applications. 
Table 2-3. Performance Summary of Ceramic Pulse-Start Metal Halide Lamps

\begin{tabular}{|c|c|c|c|c|}
\hline Lamp Power & CRI & CCT & Initial Efficacy & Mean Efficacy \\
\hline (watts) & $(\mathbf{R a})$ & $\begin{array}{c}\text { ( } \text { Kelvin) } \\
\text { (lumens per watt) }\end{array}$ & (lumens per Watt) \\
\hline 20 & $81-83$ & $3000-3000$ & $80-85$ & $53-64$ \\
\hline 39 & $82-90$ & $3000-4200$ & $82-87$ & $59-70$ \\
\hline 50 & $88-88$ & $2900-3000$ & $76-82$ & $53-57$ \\
\hline 70 & $80-95$ & $3000-4200$ & $74-117$ & $56-88$ \\
\hline 100 & $83-88$ & $3000-3000$ & $87-92$ & $63-67$ \\
\hline 150 & $80-95$ & $3000-4200$ & $73-103$ & $55-83$ \\
\hline 250 & $85-94$ & $3000-4200$ & $88-100$ & $70-80$ \\
\hline 320 & $88-90$ & $3900-4100$ & $94-117$ & $75-88$ \\
\hline 350 & $90-90$ & $4000-4000$ & $91-94$ & $73-75$ \\
\hline 400 & $82-92$ & $3000-4200$ & $90-103$ & $72-78$ \\
\hline
\end{tabular}

Source: GE and Osram-Sylvania Catalogues, 2010.

\subsubsection{Low Pressure Sodium Lamps}

The light produced in a LPS lamp comes from vaporized sodium contained in the arc tube. At low pressure, all the light produced by the arc appears as yellow light. Due to the fact that the human eye has its maximum sensitivity near this range of the color spectrum, yellow lamps tend to have high efficacies (i.e., lumen per watt ratios). The low pressure arc tube is similar to that of a fluorescent tube lamp, only without the phosphor coating and using sodium in place of mercury. Due to the presence of sodium, the glass tube has a special sodium-resistant internal coating. The U-shaped T-17 and T-21 bulb shapes are contained inside a glass outer lamp which maintains a vacuum, and which has an infrared reflective coating to reflect infrared light and help maintain correct operating temperature.

Low pressure sodium lamps are commonly found in wattages ranging from 18 to 180 watts. At the highest wattage ratings, LPS lamps achieve efficacies approaching 200 lumens per watt, and is therefore the most efficient light source available. However, it achieves this efficacy by emitting virtually monochromatic light, consisting of a double line at $589.0 \mathrm{~nm}$ and $589.6 \mathrm{~nm}$. In order to obtain the maximum efficacy of the conversion of the electrical input to the arc discharge into light, the vapor pressure of the sodium must be approximately of $0.7 \mathrm{~Pa}$, which corresponds to an arc tube bulb wall temperature of approximately $260^{\circ} \mathrm{C}\left(500^{\circ} \mathrm{F}\right)$. Any deviation from the vapor pressure $(0.7 \mathrm{~Pa})$ degrades lamp efficacy.

CRI values are not defined for this light source, as the source doesn't render color. However, while the yellow light output makes LPS lamps unsuitable for many general interior lighting applications, this light source is used commonly in tunnels, bridge underpasses, area floodlighting, railway crossing, airport and security lighting where color-rendering is not critical. 
These lamps require a dedicated ballast and ignitor, and they cannot be used in or above hazardous zones due to the fact that a fire could result from accidental breakage.

Lumen depreciation is very small, with the lamp experiencing virtually no degradation in light output over its lifetime. Rated lamp life ranges from 16,000 to 18,000 hours. Low pressure sodium lamps do not have a starting electrode or an igniter, instead these lamps require an open circuit voltage of approximately three to seven times the lamp operating voltage to start and sustain the arc discharge. The warm-up time to full light output is 7 to 15 minutes. The hot reignition is just a few seconds (as opposed to minutes for HID sources). The low-pressure sodium lamp contains no mercury.

Although LPS lamps have carved out a niche in certain applications, it is represents a small share of the market and with the advent of new long-life fluorescent lamps (e.g., Philips' 90,000 hour T8 lamp) and long-life solid-state light sources, remaining LPS installations may be under threat. According to the installed stock estimates contained the US Lighting Market Characterization Report, Volume I (DOE, 2002), LPS lamps represented approximately 4\% of all HID lamps installed in 2001. So although LPS lamps offer the highest efficacy of any light source, in practical terms it is a marginal lamp due to its poor quality light, and it is likely to be gradually replaced with new and better technologies.

\subsection{National Efficacy Regulation HID Lamps}

There are two national regulatory activities that relate to, and/or impact HID lamps being installed in the United States. The first is a requirement from the Energy Policy Act of 1992 which requires DOE to conduct a determination analysis on whether to develop minimum efficiency performance requirements for HID lamps. The second is a requirement from the Energy Independence and Security Act of 2007 which requires metal halide fixtures to incorporate ballasts of certain efficiencies.

\subsubsection{Energy Policy Act of 1992 - HID Lamp Determination}

HID lamps are a federally covered product under the authority of Section 346 of the Energy Policy and Conservation Act (EPCA) (42 U.S.C. 6317), which states:

Sec. 346. Energy conservation standards for high-intensity discharge lamps, distribution transformers, and small electric motors

(a) High-intensity discharge lamps and distribution transformers

(1) The Secretary shall, within 30 months after October 24, 1992, prescribe testing requirements for those high-intensity discharge lamps and distribution transformers for which the Secretary makes a determination that energy conservation standards would be technologically feasible and economically justified, and would result in significant energy savings.

(2) The Secretary shall, within 18 months after the date on which testing requirements are prescribed by the Secretary pursuant to paragraph (1), prescribe, by rule, energy conservation standards for those high-intensity 
discharge lamps and distribution transformers for which the Secretary prescribed testing requirements under paragraph (1).

(3) Any standard prescribed under paragraph (2) with respect to high-intensity discharge lamps shall apply to such lamps manufactured 36 months after the date such rule is published.

The Secretary of Energy therefore conducted a determination analysis on whether energy conservation standards for HID lamps are technologically feasible and economically justified, and would result in significant energy savings. On June 16, 2010, the Assistant Secretary Cathy Zoi issued a Determination that energy conservation standards are warranted, and therefore DOE is initiating work on a test procedure and energy conservation standards. 75 FR 37975 (July 1, 2010). In the Federal Register notice, it states: "Based on its analysis of the available information, DOE has determined that energy conservation standards for certain HID lamps appear to be technologically feasible and economically justified, and would likely result in significant energy savings.”

Thus, although there are no Federal regulatory minimum standards in place for HID lamps, it appears likely that DOE will develop and issue minimum standards for HID lamps in the next few years. These regulations, if adopted, would apply to lamps manufactured starting in approximately 2017.

\subsubsection{Energy Independence and Security Act of 2007 - Metal Halide Fixtures}

Section 324(e) of the Energy Independence and Security Act of 2007 (Pub. L. 110-140), amended the Energy Policy and Conservation Act (EPCA) (42 U.S.C. 6291 et seq.) to prescribe mandatory minimum efficiency levels for pulse-start metal halide ballasts, magnetic probe-start ballasts, and nonpulse-start electronic ballasts that operate lamps rated greater than or equal to 150 watts (W) but less than or equal to 500W. (42 U.S.C. 6295(hh)) These standards apply to metal halide lamp fixtures manufactured on or after January 1, 2009, requiring that these new fixtures must contain:

- Pulse Start Metal Halide ballast with a minimum efficiency of 88\% ;

- Magnetic Probe Start metal halide ballast with a minimum efficiency of 94\%; or

- Non-Pulse Start electronic ballast with a minimum efficiency of 92\% for wattages greater than 250 watts and $90 \%$ for wattages less than or equal to 250 watts.

Exceptions to these requirements are:

- Fixtures with regulated lag ballasts

- Fixtures that use electronic ballasts that operate at 480 volts

- Fixtures that are rated for 150 watt lamps

- Fixtures that are rated for use in wet locations

- Fixtures that contain a ballast that is rated to operate at ambient air temperatures of $50^{\circ} \mathrm{C}$.

This will essentially make most Probe Start fixtures a thing of the past, and one can expect that all new Metal Halide fixtures will be of the Pulse Start technology. 


\section{Research and Development of HID Lamps}

In this section, each of the HID lamp technologies is reviewed, and the status of the research and development efforts associated with the lamp types is discussed. The emphasis of this section is on metal halide lamps, and specifically, ceramic metal halide lamps, which are the focus of industry's research into HID lamps.

\subsection{Mercury Vapor Lamps}

Mercury vapor lamps are considered a lamp technology that is being gradually phased out. This technology was first commercialized in the 1930's and is not receiving any R\&D investment at this stage. The lamps are still produced by the major lamp manufacturers as global demand is strong, particularly in developing countries, however shipments are in a slow decline and the expectation is that regulatory mechanisms and market forces will ultimately phase out the MV lamp over the next decade or two. For instance, in Europe, a regulation has been passed which will eliminate MV lamps from the European market starting in 2013.

In North America, MV has been a popular light source for street lighting because the lamps gradually get dimmer over their service life, but they seldom simply extinguish. The research into MV lamps as a family of HID lamps has stopped because this technology is considered mature and the next-generation white-light HID lamp is considered to be $\mathrm{MH}$ technology. $\mathrm{MH}$ lamps offer higher efficacy, better quality white-light, and recently, long operating lives, thus their value proposition as a white-light HID source is sufficiently strong that the market will move to MH eventually. In the long term, through both MEPS and end-user life-cycle cost awareness, MV lamps will be eliminated from the market. Thus, research into improving the efficacy (lumens per watt) of MV lamps has ceased, and no improvement in efficacy is anticipated for MV lamps. In fact, according to research published by OSRAM, the efficacy of MV lamps has not improved since 1980 (see Figure ES-1).

\subsection{High Pressure Sodium Lamps}

High pressure sodium lamps are an HID technology that continues to receive some level of R\&D investment, although the focus is no longer on efficacy improvement. HPS technology is considered to be "mature" and generally optimized for the applications where it is used. Research in recent years has been to develop solutions to stop the "cycling" of the lamp at the end of its life where the ballast continually attempts to restrike the lamp and in the process contributes to premature ballast failure. This technology to prevent end-of life cycling is now commercialized by all the major lamp manufacturers.

A HPS lamp is a relatively simple lamp. It has a ceramic arc tube, no halide salts, just metallic sodium that provides a narrow wavelength of light in the yellow/orange range which gives these lamps their characteristic color. HPS is positioned as a reliable, efficient, low operating and maintenance cost light source. It is still the lamp of choice for major roads and intersections, although due to its color characteristics, it is not as popular in residential streets.

The efficacy of the lamp is already more than 150 lumens per watt, and given the limited amount of research investment, the experts interviewed did not anticipate any further breakthroughs in 
efficacy for HPS. The efficacy trade-off relates to the pressure of the xenon gas inside the arc tube and how easily the lamp starts. If a lamp designer increases the pressure, they can achieve a longer operating life and higher efficacy, however it becomes more and more difficult to start the lamp. The HPS lamps manufactured are designed to operate on the ballasts in the field, which have a set ignition level. In addition, manufacturers have incorporated ignition aids into the arc tube, such as active and passive antennas which are built directly into the ceramic that facilitate starting the lamp. These features have enabled longer life, better performance and the elimination of mercury from HPS lamps.

A new area where HPS technology is advancing that does not have to do with efficacy, but does relate to energy savings is through dimming ballasts. With the development of new and better electronic control gear, new products have been introduced to market that offer a $30-50 \%$ dimming for HPS which reduces their power consumption. Typically, these dimming systems might be installed on roadway lighting systems with timers, lowering the light level during the middle of the night when traffic volumes are reduced (e.g., 12am to 5am), or in warehouses tied to motion sensors that lower light levels when areas of the facility are not being utilized.

Finally, a notable emerging niche application for HPS lamps is in the agricultural sector, specifically in greenhouses where produce and vegetables are cultivated year-round. The lamps are good in this application because they offer very high lumens per watt of energy, providing sufficient light for growing crops year-round.

The research and development work on HPS is marked on the technology maturity continuum as being at the Commercialization and Sales part of the spectrum. This incremental research on a mature technology provides features or attributes that differentiate the HPS lamps for specific niche applications in the market.

\begin{tabular}{|c|c|c|c|c|c|c|}
\hline \multicolumn{7}{|c|}{ Technology Maturity Stage - HPS Lamp } \\
\hline $\begin{array}{c}\text { Basic Science } \\
\text { Research }\end{array}$ & $\begin{array}{c}\text { Applied } \\
\text { Research }\end{array}$ & $\begin{array}{c}\text { Exploratory } \\
\text { Development }\end{array}$ & $\begin{array}{c}\text { Advanced } \\
\text { Development }\end{array}$ & $\begin{array}{c}\text { Engineering } \\
\text { Development }\end{array}$ & $\begin{array}{c}\text { Product } \\
\text { Demonstration }\end{array}$ & $\begin{array}{c}\text { Commercialization } \\
\text { and Sales }\end{array}$ \\
\hline & & & & & & \\
\hline
\end{tabular}

\subsection{Quartz Metal Halide Lamps}

Quartz metal halide lamps are one type of MH lamp which have their arc tube capsules made out of quartz. These are common lamps, however they are no longer a focus area of R\&D for manufacturers because of the material limitations of quartz. These lamps have been surpassed in performance by ceramic arc tube technology, which offers higher efficacies and better color rendering thanks to their higher operating temperatures. Quartz $\mathrm{MH}$ lamps tend to be limited in color temperature, they have a CRI around 65, and they do not dim well (i.e., the light output shifts on the color spectrum, so the dimmed light no longer matches the light output observed at full brightness). 
The quartz arc tube is a constraint which limits the metal halides that can be added to the arc tube (because they react with quartz), and the operating temperature isn't as high as ceramic. There are some manufacturers offering very high efficacies in quartz $\mathrm{MH}$ lamps, perhaps 110 or 115 lumens per watt initial efficacy, but the capsules are really be operated beyond what is reasonable for them, thus the lumen depreciation will be high and the lifetime of the lamp will be considerably shorter. Quartz capsule MH lamps are perceived as a mature technology that has really achieved its technological limits.

There have been some companies that have looked to develop a $\mathrm{MH}$ lamp as a replacement to a HPS system, but the results have not been very good. MH lamps typically operate on a 130 volt system and HPS typically operate on a $100 \mathrm{~V}$ system, which is a less favorable voltage for $\mathrm{MH}$. In addition, quartz metal halide requires the use of thoriated tungsten filaments, which are radioactive, thus they are a concern for manufacturers, particularly relating safe handling and containment of this material. In general, when compared to the ceramic $\mathrm{MH}$ lamps, quartz $\mathrm{MH}$ is perceived as having a higher probability of rupture and a lower level of reliability.

Ceramic $\mathrm{MH}$ lamps are replacing quartz (and indeed, halogen reflector lamps) at wattages less than 200W. In the 250 and 400W market, quartz MH lamps have been stable because the price differential between quartz and ceramic can be quite high, however the researchers interviewed indicate that this is about to change. There are new, very efficient ceramic MH lamps entering the market now, which offer a compelling value proposition and are likely to further shift the metal halide lamp market from quartz to ceramic. Overall, research for general lighting applications of quartz MH lamps is perceived to have stopped, and researchers were not aware of any potential further efficacy gains for quartz capsule MH lamps.

\subsection{Ceramic Metal Halide Lamps}

Ceramic metal halide lamps have their arc tube capsule constructed out of a ceramic material, and they are perceived as the next generation of white-light HID lamps (i.e., the evolution from $\mathrm{MV}$ to quartz $\mathrm{MH}$, and now from quartz $\mathrm{MH}$ to ceramic $\mathrm{MH}$ ). There is considerable on-going research in this group of HID lamps, and manufacturers believe there is still a lot of room for performance improvement.

Improvements in the metal halide lamp family are not discrete, separable measures - such as, an improvement in phosphors or a better electrode in a fluorescent lamp. For MH lamps, and indeed HID lamps in general, the improvements are all linked to the performance of the arc tube, and within that tube, the chemistry, the pressure and the temperature of the reaction. So the interaction of many variables come together to enable more favorable arc tube operating characteristics and a subsequent improvement in lamp efficacy. For ceramic MH lamps, the innovation of changing the arc-tube containment material from quartz to ceramic enabled a new, broader range of metal halides to be used and higher operating temperatures and pressures. Taken together, these improvements created a new family of MH lamps - ceramic MH - which offer better color quality, longer operating life and higher efficacy than quartz MH.

As a replacement for halogen reflector lamps, industry had invested in the development of very low wattage ceramic metal halide reflector lamps. The value proposition for ceramic MH lamps 
in this application was the combination of excellent color rendering, longer operating life (typically 3-5x halogen) and higher efficiency (typically 4-6x halogen). For example, 75W and 100W halogen lamps were replaced with 15W and 20W ceramic metal halide lamps that had equivalent lumen output and excellent color rendering. These lower wattage applications were viable because as the wattages went down, the efficacy of the lamps only decreased slightly. However, researchers were clear that further research into lower wattage ceramic $\mathrm{MH}$ is unlikely for two reasons - first, the ceramic $\mathrm{MH}$ system had a high first cost compared to the incumbent halogen and secondly, it is expected that light emitting diode (LED) lamps will eventually come to dominate retail display lighting.

Ceramic systems are currently manufactured up to 400 watts, and although that's the highest wattage available today, there are no technical limitations or reasons why ceramic lamps cannot be made at 1000 watts or higher. Part of the reason industry started by developing ceramic $\mathrm{MH}$ lamps in the sub-400 watt market first is because these wattages represent the highest volume. For example, as a replacement to the 400 watt quartz $\mathrm{MH}$ high-bay luminaire that might be found in a big box retail establishment, Philips offers a 315 watt ceramic MH lamp, which achieves approximately 115 lumens per watt and provides the same light output as the original lamp. This represents a 20\% improvement in efficacy over standard quartz MH lamps.

Manufacturers have developed ceramic $\mathrm{MH}$ lamps that are able to be retrofitted into any quartz MH lamp socket - whether it's an open or closed fixture, a probe or pulse start. These lamps operate on the existing ballast, produce the same amount of light, of a better quality and yet consume less power. The wattage of the lamps is reduced by changing the lamp power factor, and the operating lifetime is extended from 15,000 to 20,000 hours by shifting to the ceramic arc tube.

Recently, Philips made a public announcement about a new innovation in ceramic $\mathrm{MH}$ - the "unsaturated lamp". ${ }^{10}$ This lamp addresses the problem of the small pool of liquid salt that remains in a standard ceramic MH lamp arc tube during operation. That pool of liquid limits the light characteristics such as efficacy and color quality, and reduces lamp lifetime. Through changes to the arc tube, pressure and operating temperature, the unsaturated lamp resolves these issues by keeping all the halide salts in the gaseous phase, even when dimming. Another critical innovation was the sealing of the electrodes into the arc tube iridium feedthroughs and no frit seals. This patented step of the manufacturing process uses materials that match the expansion coefficient of ceramic arc tube itself, thereby creating a new reliable seal for the electrodes. To avoid the problem of pooled liquid salt, the lamp is dosed with micrograms of halides rather than the standard milligrams, which reduces the reaction and attack on the ceramic arc tube, improving lamp lifetime. Plus, this technology has the potential to offer high performance characteristics such as fast run-up to full brightness ( $<30$ seconds) due to a lower arc tube mass, dimmability without color shift, longer operating life, mercury free lamps, hot re-strike and miniaturization. With this new development in ceramic MH lamps, the work is now focusing on developing a new family of unsaturated ceramic metal halide lamps.

\footnotetext{
10 "Unsaturated ceramic metal halide lamps: A new generation of HID lamps” by J. Hendricx, J. Vrugt, C. Denissen, and J. Suijker, published in the Proceedings of the 12th International Symposium on the Science and Technology of Light Sources and the 3rd White LED Conference, July 11-16, 2010, Eindhoven, The Netherlands.
} 
Manufacturers are offering commercially available ceramic MH lamps that are operating at 120 lumens per watt (initial). Researchers interviewed agreed that they could envision this product being optimized and incrementally improved over the next 2 to 4 years to go from $120 \mathrm{~lm} / \mathrm{W}$ to $150 \mathrm{~lm} / \mathrm{W}$. Thus, by 2013-2014, they would expect to see commercially available ceramic metal halide lamps that offer $150 \mathrm{~lm} / \mathrm{W}$, and which offer high quality white-light in a package that would be more than 20,000 hours of operating life.

These new lamps will study new metal halides that offer higher efficiency values and better color emission spectra. Due to the fact that the unsaturated arc tube will avoid the liquid-phase of the halides, other materials previously not used could now be tried in the arc tube. The new lamps will also take advantage of much higher vapor pressures in the arc tube. These higher vapor pressures open up the possibilities for dimming the lamp, for higher efficacy and for removing other restricted materials such as mercury and thoriated tungsten which is used in the quartz $\mathrm{MH}$ lamp.

Moving beyond this technology, manufacturers also discussed the 'next generation' of performance, which would be to eliminate the electrode in the lamps. Electrode-less operation would enable the lamp to achieve potentially $200 \mathrm{~lm} / \mathrm{W}$, through the elimination of the losses from the electrodes and the optimization of the lamp system itself around this new style of operation. There are three companies who own intellectual capital in this space - Ceravision (UK), LG Electronics (South Korea) and Luxim (California, US). Each of these companies offers an electrode-less lamp, however the efficacies are currently around 85 to $90 \mathrm{~lm} / \mathrm{W}$. These products are operational, but according to the industry sources interviewed, they are not yet optimized.

There are some practical considerations to take into account for electrode-less operation, including driver efficiency and managing electro-magnetic interference (EMI). There is also concern that if industry is able to achieve $150 \mathrm{~lm} / \mathrm{W}$ with traditional technologies, the payback and value proposition of going to $200 \mathrm{~lm} / \mathrm{W}$ may not be as compelling because it would involve a completely new driver, luminaire and optics, and would be based around an unfamiliar, new technology.

Given this input from industry with respect to research into next generation MH lamps, there are two stages of technology maturity to be marked on the continuum. The first would relate to incremental improvements in the existing commercialized stock around new arc tube shapes, halide salt combinations and electrode design. The second stage relates to the new unsaturated arc tube, which continues to undergo further engineering development. This product is the focus of experiments with alternative halides and other changes to the system that will add incremental improvements in performance which should eventually be commercialized.

\begin{tabular}{|c|c|c|c|c|c|c|}
\hline \multicolumn{7}{|c|}{ Technology Maturity Stage - Ceramic MH Lamps } \\
\hline $\begin{array}{c}\text { Basic Science } \\
\text { Research }\end{array}$ & $\begin{array}{c}\text { Applied } \\
\text { Research }\end{array}$ & $\begin{array}{c}\text { Exploratory } \\
\text { Development }\end{array}$ & $\begin{array}{c}\text { Advanced } \\
\text { Development }\end{array}$ & $\begin{array}{c}\text { Engineering } \\
\text { Development }\end{array}$ & $\begin{array}{c}\text { Product } \\
\text { Demonstration }\end{array}$ & $\begin{array}{c}\text { Commercialization } \\
\text { and Sales }\end{array}$ \\
\hline & & & & & & \\
\hline
\end{tabular}




\subsection{Electrodeless HID Lamps}

In traditional HID lamps, an electric field is generated between two electrodes that initiate and maintain the arc discharge. However, this method of initiating the arc and maintaining current flow causes degradation and sputtering of the electrodes, eventually resulting in lamp failure. When an HID lamp starts and during warm-up, the coating on the electrode and some of the electrode material sputters off, which darkens the arc tube and reduces lumen maintenance. Due to the fact that an electrodeless lamp does not have any electrodes, it does not suffer from these degradation and failure mechanisms.

As discussed in section 3.4, electrodeless HID lamps eliminate the need for electrodes and offer the potential for achieving 'next generation' of performance. Electrode-less operation could enable the lamp to achieve up to $200 \mathrm{~lm} / \mathrm{W}$ through the elimination of the losses from the electrodes and optimization of the optical system around this new light source. There are three companies who own intellectual capital in this space - Ceravision (Milton Keynes, UK), LG Electronics (Seoul, South Korea) and Luxim (California, US).

Ceravision's technology is termed "high efficiency plasma”, and is an electrodeless lighting system that uses radio frequency in the microwave range to create a high intensity plasma discharge. Ceravision's system consists of four integrated components - a quartz radio frequency resonator and integral plasma burner (note: this is the light source); a transition unit that couples the radio frequency microwaves from the generator to the source; a radio frequency microwave generator which creates the waves and an AC power supply to operate the generator. The integrated plasma burner and quartz resonator contain an inert gas and metal halide salts. As the radio frequency microwave energy resonating within the lamp ionizes the gas, it forms a plasma that combines with the metal halide to vaporize the metal halide salts, emitting an intense, bright, broad-spectrum light. Ceravision has developed an indoor high-bay luminaire, and is looking at other applications, including street lighting and area lighting fixtures. For more information, visit Ceravision’s website: http://www.ceravision.com/Page/Home

LG Electronics purchased the patents from a company that was previously based in Maryland called Fusion Lighting. Fusion went bankrupt in 2003, and LG Electronics purchased the technology and has been developing sulphur-based light sources. Their product range includes floor lighting, street lighting and high-bay luminaires. They also offer a light tube technology which can be used to distribute this light over a broad area. The four parts of the LG Electronics system are similar to that of Ceravision, in that they have a power supply, a microwave generator, a waveguide, a cavity resonator and a lamp that contains the salts that are heated to emit light. The diagram below depicts the steps of this process. For more information, visit LG Electronic's website: http://www.lge.co.kr/cokr/product/lighting/light_01
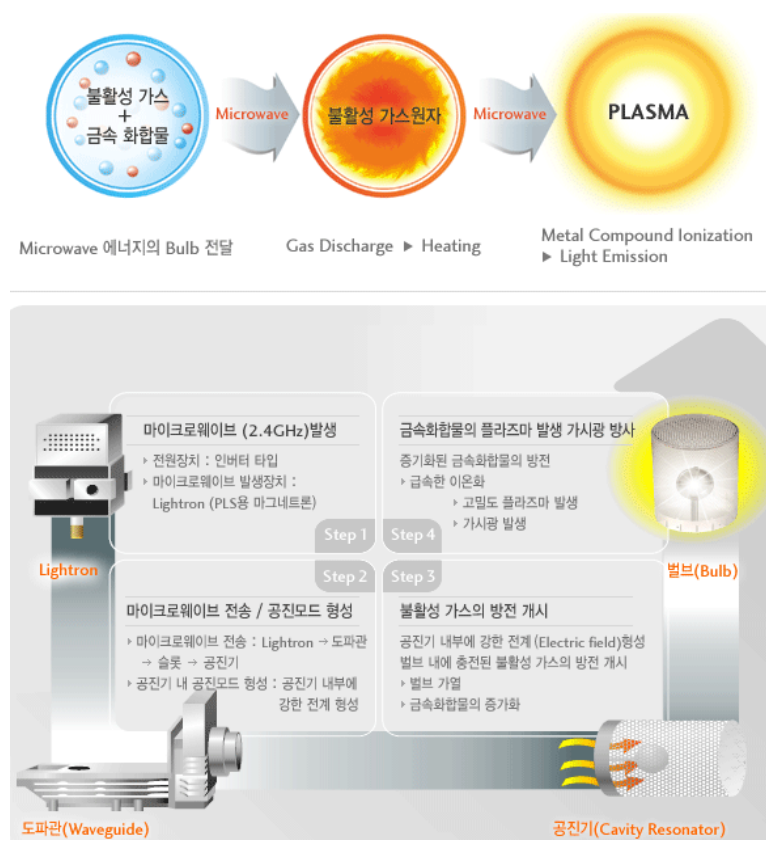
list.jsp (note: much of the information is presented in Korean).

The Luxim system is similar to Ceravision's in that they use a microwave generator and wave guide to excite a capsule of metal halide salts that emits light. Luxim brands their product as solid-state high-intensity discharge lighting, since they use a solid state microwave generator rather than a magnetron. Luxim also recognizes and markets the value proposition of being electrodeless. Their latest high-bay luminaire, the Tesla 400 has a rated system efficacy of 73 lumens per watt. Part of the problem with Luxim's technology is the opaque, ceramic wave guide which adsorbs part of the light emission. Ceravision has now innovated on that earlier generation technology and is now using clear quartz waveguides in their system. For more information about Luxim, visit their website at: http://www.luxim.com/

Looking across the three companies and their technologies, each offers an electrode-less lamp, however the efficacies are currently from 73 to $90 \mathrm{~lm} / \mathrm{W}$. These products are operational, but according to the industry researchers interviewed, they are not yet optimized. The technology maturity for electrodeless technology, which - although there are some commercialized products available - has been marked as between Advanced Development and Product Demonstration on this graph as it has work that remains to be done on the burners, drivers, luminaires / optics and other critical system aspects.

\begin{tabular}{|l|c|c|c|c|c|c|}
\hline \multicolumn{7}{|c|}{ Technology Maturity Stage - Electrodeless Lamp } \\
\hline $\begin{array}{c}\text { Basic Science } \\
\text { Research }\end{array}$ & $\begin{array}{c}\text { Applied } \\
\text { Research }\end{array}$ & $\begin{array}{c}\text { Exploratory } \\
\text { Development }\end{array}$ & $\begin{array}{c}\text { Advanced } \\
\text { Development }\end{array}$ & $\begin{array}{c}\text { Engineering } \\
\text { Development }\end{array}$ & $\begin{array}{c}\text { Product } \\
\text { Demonstration }\end{array}$ & $\begin{array}{c}\text { Commercialization } \\
\text { and Sales }\end{array}$ \\
\hline & & & & & & \\
& & & & & & \\
\hline
\end{tabular}

\subsection{LED Technology}

Light emitting diodes (LEDs) are an emerging technology that has recently started to be considered as a substitute in certain HID lighting applications, such as street lighting. LED devices recently achieved a milestone, in that one of the major manufacturers achieved $208 \mathrm{~lm} / \mathrm{W}$ in a single power white LED in the laboratory. Experts involved in research have projected that LEDs can offer, at a device level, a maximum efficacy of $250 \mathrm{~lm} / \mathrm{W}$ (University of California Santa Barbara) to $280 \mathrm{~lm} / \mathrm{W}$ (Philips Lighting). The efficacy improvement of LEDs has occurred at a much more rapid pace than conventional light sources such as fluorescent and incandescent lamps, and it promises to exceed the performance of all other conventional technologies within five years. Furthermore, in addition to being highly energy-efficient, good quality LEDs offer the market long life (in excess of 50,000 hours), have no filament or glass envelope to break, offer a small form factor and are mercury-free in their construction. Due to the fact that these are solid-state devices and do not emit any heat in their light emission, good thermal management of LED products will be critical to ensuring these performance attributes are met.

The US Department of Energy's publishes an annual Solid-State Lighting multiyear program plan that projects a rapid reduction in the price of LED lighting (DOE, 2011). This forecast 
anticipates that manufacturing costs will continue to decrease at the same time that the light output per device and the lumens per watt are increasing, particularly at high drive currents required for general lighting applications. Experts are also looking to make LED lamps compatible with standard dimming circuits, designed for use with incandescent lamps. Through proper driver electronics design, an LED lamp can be made dimmable over a wide range of light output - either through lower current or by modulating the power supplied to the LED.

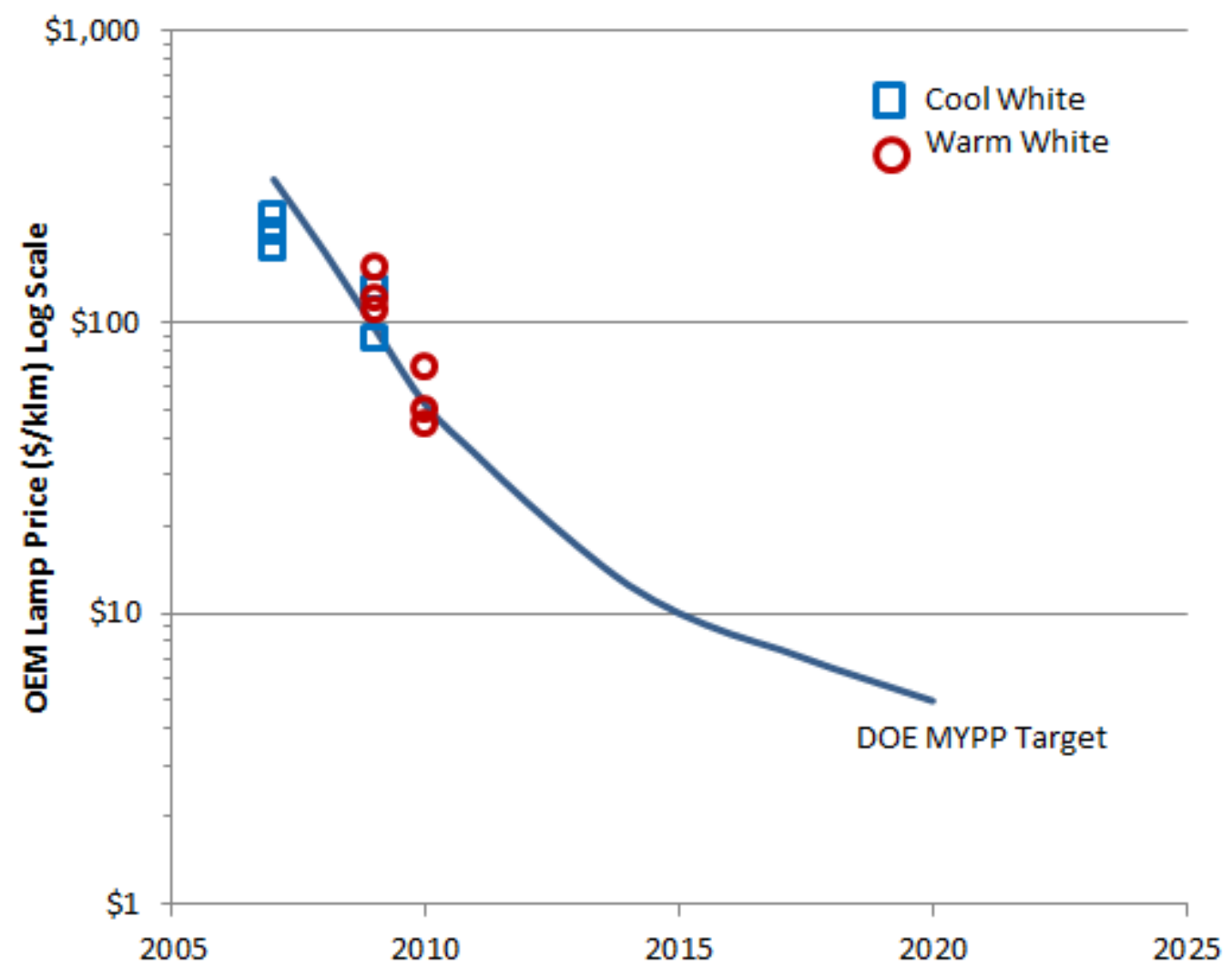

Figure 3-1. Projected OEM Price for White Light LED Lamp, Integrally Ballasted

Researchers have an ambition to manufacture $250 \mathrm{~lm} / \mathrm{W}$ white-light RGB LED systems that run on AC-current, have 100,000 hour lifetimes, offer a rugged form-factor, contain no mercury, are versatile and are cool in operation. Such devices would have the potential to dramatically transform the lighting market. These technologies will increase the competition between the lighting technologies, and the replacement of HID street lamps by LED sources may move from a novel pilot project to the mainstream technology option.

The technology maturity continuum for LEDs could be shown to span the entire range from basic science right through to commercialization and sales. This is the case because there is primary, basic science research now into new materials and processing technologies that will impact how LEDs are manufactured and used in the future. There is also engineering development, product demonstration (like street lights) and commercialization and sales. LED luminaires are available for purchase and installation today. For this reason, and to reflect the 
fact that there is an enormous amount of investment into solid-state lighting and LED lighting in particular, the bar has been shown to cover the continuum.

\begin{tabular}{|c|c|c|c|c|c|c|}
\hline \multicolumn{7}{|c|}{ Technology Maturity Stage - LED Technology } \\
\hline $\begin{array}{c}\text { Basic Science } \\
\text { Research }\end{array}$ & $\begin{array}{c}\text { Applied } \\
\text { Research }\end{array}$ & $\begin{array}{c}\text { Exploratory } \\
\text { Development }\end{array}$ & $\begin{array}{c}\text { Advanced } \\
\text { Development }\end{array}$ & $\begin{array}{c}\text { Engineering } \\
\text { Development }\end{array}$ & $\begin{array}{c}\text { Product } \\
\text { Demonstration }\end{array}$ & $\begin{array}{c}\text { Commercialization } \\
\text { and Sales }\end{array}$ \\
\hline & & & & & & \\
\hline & & & & & & \\
\hline
\end{tabular}




\section{Screening Analysis Preview}

The purpose of the screening analysis is to review the technology options discussed in Chapter 3 which improve the efficacy of HID lamps and determine which of these options would be able to be evaluated in an energy conservation standards rulemaking. The screening analysis in the context of this report is a preliminary assessment based on non-detailed information provided by the interviews with manufacturers. The findings of this review are indicative only, and should not be taken as a comprehensive screening analysis, such as DOE conducts in a regulatory rulemaking.

\subsection{Introduction}

The screening analysis is conducted by applying a set of screening criteria to the design options identified as means of making a fluorescent lamp more efficient. The criteria that shall be applied when conducting a screening analysis are contained in the US Code of the Federal Register, (10 CFR Part 430, Subpart C, Appendix A at 4(a)(4) and 5(b)):

(1) Technological feasibility. Technologies incorporated in commercial products or in working prototypes will be considered technologically feasible;

(2) Practicability to manufacture, install, and service. If mass production of a technology in commercial products and reliable installation and servicing of the technology could be achieved on the scale necessary to serve the relevant market at the time of the effective date of the standard, then that technology will be considered practicable to manufacture, install, and service.

(3) Adverse impacts on product utility or product availability. If a technology is determined to have significant adverse impact on the utility of the product to significant subgroups or consumers, or result in the unavailability of any covered product type with performance characteristics (including reliability), features, sizes, capacities, and volumes that are substantially the same as products generally available in the U.S. at the time, it will not be considered further.

(4) Adverse impacts on health or safety. If it is determined that a technology will have significant adverse impacts on health or safety, it will not be considered further.

This section discusses the energy-efficiency measures identified in Chapter 3 of this report, and describes how the criteria may or may not apply to each of the technology options. These measures are discussed in a general way, without focusing on specifics.

\subsection{Screening of Efficiency Measures}

There are three technology options discussed in this report which contemplate improving the efficacy of HID lamps. These measures are discussed at a higher-level, aggregating several technology interventions. The following table presents these options, and then has a column for each of the options that is indicative of whether this technology is likely to comply with the 
requirements of a screening analysis. Following the table, a discussion ensues on the technology options which appear to have issues pertaining to the screening analysis criteria.

Table 4-1. Initial Screening Analysis of Technology Options Discussed

\begin{tabular}{|l|c|c|c|c|}
\hline $\begin{array}{c}\text { Technology } \\
\text { Option }\end{array}$ & $\begin{array}{c}\text { Technical } \\
\text { Feasibility }\end{array}$ & $\begin{array}{c}\text { Practicability to } \\
\text { Manuf., Install } \\
\text { and Service }\end{array}$ & $\begin{array}{c}\text { Adverse Impacts } \\
\text { on Utility or } \\
\text { Availability }\end{array}$ & $\begin{array}{c}\text { Adverse Impacts } \\
\text { on Health or } \\
\text { Safety }\end{array}$ \\
\hline $\begin{array}{l}\text { HPS Lamp } \\
\text { Measures }\end{array}$ & No issue & No issue & No issue & No issue \\
\hline $\begin{array}{l}\text { Unsaturated } \\
\text { MH Lamp }\end{array}$ & No issue & No issue & No issue & No issue \\
\hline Electrode-less & No issue & No issue & No issue & No issue \\
\hline
\end{tabular}

Of the three technology options considered, none of them appear to have any issues that would warrant screening them out of an engineering analysis. All three are technologies used in the market today and the research being done is focused on incremental improvements to these commercially available technologies.

While the unsaturated ceramic metal halide lamp is an emerging new technology, it is engineering development and there are no known potential impacts that might force this premium technology to be screened out of the analysis.

Similarly, electrode-less technology has certain parts of its system that are classified as “Advanced Development”, there are manufacturers such as LG Electronics who are producing and manufacturing this technology. For this reason, the technology is feasible, practical to manufacture and install, and does not appear to have any adverse impacts on utility, availability or health and safety. 


\section{Manufacturers and Markets}

HID lighting has been commercially available since the 1930's in the form of mercury vapor lamps and since the 1960's in the form of metal halide and high pressure sodium lamps. Over this time period, the technology has improved its efficacy, to the point where these technologies now offer very high lumen per watt efficacy values and, for certain metal halide lamps, excellent quality white light.

\subsection{Manufacturers of HID Lamps}

The HID lamp market in the U.S. is dominated by three large global corporations who are also industry leaders in other lighting technologies, such as incandescent and fluorescent lamps:

- General Electric Consumer and Industrial North America / Venture Lighting

- OSRAM Sylvania

- $\quad$ Philips Lighting North America

While there are other smaller companies that have niche HID products and/or who compete with these three large companies, more than $80 \%$ of the HID lamps sold are produced (or branded) by these companies:

\subsection{Market Size and Shipments}

The following table provides shipment estimates for the main families of HID lamps. These are projections based on data provided to the US Department of Energy by the National Electrical Manufacturers Association (NEMA). The table provides shipments of NEMA members, which are assumed to represent the totality of shipments of HID lamps into the US market. Any other manufacturers or private-labeled fluorescent lamps sold would constitute less than $5 \%$ of the shipments presented. The shipment data from NEMA ends in 2006, and the subsequent years are projections forward based on historical trends. 
Table 5-1. Shipment Estimate for HID lamps for the U.S. Market

\begin{tabular}{|c|c|c|c|c|}
\hline Years & $\begin{array}{c}\text { MV } \\
\text { (millions) }\end{array}$ & $\begin{array}{c}\text { HPS } \\
\text { (millions) }\end{array}$ & $\begin{array}{c}\text { MH } \\
\text { (millions) }\end{array}$ & $\begin{array}{c}\text { Total Market } \\
\text { (millions) }\end{array}$ \\
\hline 2000 & 4.0 & 11.7 & 17.5 & 33.2 \\
\hline 2001 & 3.7 & 12.0 & 18.7 & 34.4 \\
\hline 2002 & 3.5 & 12.2 & 19.9 & 35.7 \\
\hline 2003 & 3.3 & 12.5 & 21.1 & 36.9 \\
\hline 2004 & 3.1 & 12.8 & 22.3 & 38.2 \\
\hline 2005 & 2.9 & 13.1 & 23.5 & 39.5 \\
\hline 2006 & 2.7 & 13.3 & 24.7 & 40.7 \\
\hline 2007 & 2.5 & 13.6 & 25.9 & 42.0 \\
\hline 2008 & 2.2 & 13.9 & 27.1 & 43.3 \\
\hline 2009 & 2.0 & 14.2 & 28.3 & 44.5 \\
\hline 2010 & 1.8 & 14.5 & 29.5 & 45.8 \\
\hline 2011 & 1.6 & 14.7 & 30.7 & 47.0 \\
\hline 2012 & 1.4 & 15.0 & 31.9 & 48.3 \\
\hline 2013 & 1.2 & 15.3 & 33.1 & 49.6 \\
\hline 2014 & 1.0 & 15.6 & 34.3 & 50.8 \\
\hline 2015 & 0.7 & 15.8 & 35.5 & 52.1 \\
\hline
\end{tabular}

Source: NEMA data; NCI forecasts based on historical projections.

\subsection{Estimate of the Installed Stock}

Taking the shipment data shown in section 5.2, an estimate of the installed stock of covered HID lamps can be prepared. The flowdiagram to the right describes the five step process followed to arrive at the estimate prepared for this study. In essence, the inventory stock model takes into account shipments of lamps over a number of years, the catalogue lifetimes for those lamps, the typical operating hours, and an S-curve failure function that is representative of HID lamps. The stock are then tracked year on year and summed together to create the total national inventory.
Lamp

Shipments

Catalogue

Lifetime

Operating

Hours

Failure

Rate

$\Sigma$ n years
Shipments of HID lamps in

the US from NEMA

Derive catalogue lifetime ( $50 \%$ failure) from manufacturer catalogues

Estimate operating hours, taking into account commercial applications

Applya known failure function for lighting products (S-curve)

Sum annual shipments over sufficient time to capture legacy years 
Concerning the failure function, the published lamp manufacturer catalogue lifetimes represent an average rating, indicative of when $50 \%$ of the lamps have failed. This means there will be some lamps that fail before the rated lifetime and some that fail afterwards. The shape of the lifetime failure curve represents an "S-curve" which rises slowly initially (indicating few lamp failures in the first half of the life), then rises rapidly through the $50 \%$ point (which is the published average lifetime) before it gradually slows down approaching $100 \%$ of failures. This curve means that very few lamps (a low percentage) will fail before the rated catalogue lifetime and similarly, a small percentage of lamps will extend beyond the rated life.

This S-Curve lamp failure function is defined by the equation

$$
y(t)=1 /\left(1+b^{-b(t-a)}\right)
$$

where:

$\mathrm{y}(\mathrm{t})$ is the fraction of the market remaining

"a” represents the time to $50 \%$ of failure "b" represents the steepness of the slope

The " $a$ " term used is defined as the catalogue life divided by the weighted operating hours and varies according to the lamp type and installation. For this study, an average of 12 hours per day, 365 days per year was used as the operating hours for all installations and a range of average lifetimes: 24,000 hours for MV; 21,000 hours for HPS; and 18,000 hours for MH. The "b" term is set at 2.0 to be indicative of typical lamp-life failure curves, having a small number of failures in the beginning, rising steeply through the $50 \%$ mark and then slowing down as it approaches $100 \%$ failures.

The table below presents the findings of this inventory stock model for the three types of HID lamps. The trends in stock follow the same trends observed in Table 5-1 above, which tend to show increasing installed stock of MH lamps and declining stock of MV lamps. By 2015, the estimated installed stock of MV lamps will be just 3.2\% of total HID lamps installed in the US.

Table 5-2. Estimate of the Installed Stock of HID Lamps in the US Market (000 units)

\begin{tabular}{|c|r|r|r|r|r|r|}
\hline Lamp & \multicolumn{1}{c|}{$\mathbf{2 0 1 0}$} & \multicolumn{1}{c|}{$\mathbf{2 0 1 1}$} & \multicolumn{1}{c|}{$\mathbf{2 0 1 2}$} & \multicolumn{1}{c|}{$\mathbf{2 0 1 3}$} & \multicolumn{1}{c|}{$\mathbf{2 0 1 4}$} & \multicolumn{1}{c|}{$\mathbf{2 0 1 5}$} \\
\hline MV & 14,137 & 12,843 & 11,555 & 10,289 & 9,066 & 7,765 \\
\hline HPS & 73,204 & 74,651 & 76,128 & 77,614 & 79,105 & 80,512 \\
\hline MH & 125,277 & 130,805 & 136,333 & 141,862 & 147,390 & 152,919 \\
\hline
\end{tabular}




\section{References}

Chapters 2 and 3, Market and Technology Assessment, High Intensity Discharge Lamp Determination Analysis, Final Determination; US Department of Energy, July 1, 2010.

Desroches, Louis-Benoit, and Karina Garbesi, 2011. Max Tech and Beyond: Maximizing Appliance and Equipment Efficiency by Design. Lawrence Berkeley National Laboratory, LBNL-4998E.

DOE, 2005. U.S. Lighting Market Characterization Volume II: Energy Efficient Lighting Technology Options; Prepared by Navigant Consulting for the US Department of Energy. September 2005.

DOE, 2011. Solid-State Lighting Research and Development; Multi Year Program Plan, March 2011 (Updated May 2011) http://apps1.eere.energy.gov/buildings/publications/pdfs/ssl/ssl_mypp2011_web.pdf

Flesch, 2006. Light and light sources: high-intensity discharge lamps. Dr.-Ing. Peter Flesch, OSRAM GmbH, Berlin Germany. Springer Press, 2006.

General Electric Lamp and Ballast Catalogue, GE Consumer and Industrial North America, May 2010.

Hendricx, 2010. "Unsaturated ceramic metal halide lamps: A new generation of HID lamps,” by J. Hendricx, J. Vrugt, C. Denissen and J. Suijker; Philips Lighting B.V.. Published in the Proceedings of the 12th International Symposium on the Science and Technology of Light Sources and the 3rd White LED Conference, July 11-16, 2010, Eindhoven, The Netherlands.

Hooker, 2010. J.D. Hooker, LampTech: The Museum of Electric Lamp Technology; London, UK. June 2010.

Kane, 2001. Revolution in Lamps: a Chronicle of 50 Years of Progress, by Raymond Kane and Heinz Sell, second edition. The Fairmont Press, Lilburn, Georgia, 2001.

Personal Communication with industry technical experts at Philips Lighting; Havells-Sylvania and OSRAM/Sylvania, June and July 2010.

Rea, 2000. The IESNA Lighting Handbook: Reference \& Application, 9th Edition. 2000. Mark S. Rea, Editor. The Illuminating Engineering Society of America: New York, New York, 2000. 